\title{
"An meine getreuen österreichischen Völker“. Das „Völker- manifest" Karls I. vom 16. Oktober 1918 - Ein später Versuch zur Abwendung des Zerfalls der Habsburgermonarchie?
}

\author{
Jakob Kathrein \\ Kerngebiet: Österreichische Geschichte \\ eingereicht bei: Ass.-Prof. Mag. Dr. Hermann J. W. Kuprian \\ eingereicht im: SS 2014 \\ Rubrik: BA-Arbeit
}

\begin{abstract}
The "Völkermanifest" of Charles I. of Austria from October 16", 1918 - A late Attempt to Avoid the Collapse of the AustroHungarian Empire?

The purpose of this paper is to examine the principal reasons for Charles I.'s enactment of his "Vökermanifest" as well as the political background and driving powers. Was the manifesto the attempt of a monarch to avoid the apparently inevitable decline of his empire? What are the circumstances of the manifesto's evolution and why did it fail? The analysis also focuses on the reactions of politics, population and the press to the manifesto's decree.
\end{abstract}

\section{Einleitung}

Als Karl I. seinem Großonkel Kaiser Franz Josef nach dessen Tod im November 1916 auf den Thron nachfolgte, standen die Vorzeichen für eine ruhige, konfliktlose Regierungszeit ungünstig. Österreich-Ungarn befand sich seit mehr als zwei Jahren mitten in einem militärischen Konflikt, der sich zu einem Weltkrieg entwickelt hatte. Auch innenpolitische Differenzen traten zunehmend in den Vordergrund. Die Habsburgermonarchie stand besonders wegen der ungelösten Nationalitätenprobleme vor ihrer Auflösung. Eines war klar: Es mussten grundlegende Veränderungen und Neuerungen erfolgen, um das Reich vor dem Zerfall zu bewahren. Schon bei seinem Regierungsantritt brachte Karl sein oberstes Ziel, Frieden zu schließen, zum Ausdruck: 
„Ich will alles tun, um die Schrecknisse und Opfer des Krieges in ehester Frist zu bannen, die schwervermißten Segnungen des Friedens meinen Völkern zurückzugewinnen, sobald es die Ehre unserer Waffen, die Lebensbedingungen meiner Staaten und ihrer treuen Verbündeten und der Trotz unserer Feinde gestatten werden."1

Es war inm bewusst, dass sich dringend notwendige, nachhaltige Reformen im Krieg nur schwer umsetzen ließen.

Im Mittelpunkt dieser Bachelorarbeit steht das "Völkermanifest”, das von Karl I. am 16. Oktober 1918 erlassen und einen Tag später in einer Extra-Ausgabe der Wiener Zeitung veröffentlicht wurde. Es bildet die zentrale Quelle der Arbeit. Der britische Historiker Gordon Brook-Shepherd bezeichnete das „Völkermanifest“ in seiner Biographie Karls I. als dessen „weitreichendste Regierungshandlung”. Brook-Shepherd ging sogar noch einen Schritt weiter und sah es als "die weitreichendste Regierungshandlung im Leben der Doppelmonarchie". ${ }^{2}$

Im Völkermanifest ist vom "Neuaufbau des Vaterlandes" in Form eines „Bundes der freien Völker" die Rede. Karl I. ruft damit die einzelnen Volksgruppen zur Bildung von Nationalräten auf. Doch wie ist diese Proklamation des Kaisers zu interpretieren? Von dieser Problemstellung ausgehend, werden folgende Fragestellungen formuliert: Welche Motive, realpolitischen Hintergründe und Triebkräfte standen hinter dem Völkermanifest? Wer waren die zentralen beteiligten Akteure bezüglich dessen Entstehung? Welche Reaktionen rief das Manifest hervor? Warum schlug es schlussendlich fehl?

Zu den Fragestellungen wird die Hypothese aufgestellt, dass die Auflösung ÖsterreichUngarns durch den Erlass des Völkermanifests nicht gebremst oder gestoppt, sondern sogar beschleunigt wurde. Der Aufruf Karls zur Bildung von nationalen Räten wurde zwar gehört, jedoch dazu benutzt, um von Habsburg unabhängige Staaten zu konstituieren. Das Völkermanifest bildete in diesem Sinne die Autorisierung zur Selbständigkeit, die anzustreben vormals als Hochverrat gewertet worden wäre.

\section{Forschungsstand}

Im Folgenden soll ein Blick auf einige Wissenschaftlerinnen und Wissenschaftler, die bereits das Thema "Völkermanifest" behandelten sowie auf weitere, für diese Arbeit relevante Literatur, geworfen werden. Mit dem Völkermanifest an sich setzte sich vor allem der Historiker Helmut Rumpler bereits in den 1960er-Jahren auseinander. In seiner Publikation „Das Völkermanifest Kaiser Karls vom 16. Oktober 1918. Letzter Versuch zur Rettung des Habsburgerreiches" beschäftigte er sich ausführlich mit der Entstehung dieses Dokuments, das bis dahin weitgehend unerforscht geblieben war. ${ }^{3}$ Die Arbeiten

1 Zit. n. Walter Pohl/Karl Vocelka, Die Habsburger. Eine europäische Familiengeschichte, hrsg. v. Brigitte Vacha, Wien, 1992, S. 473.

2 Gordon Brook-Shepherd, Karl I. Des Reiches letzter Kaiser. Glanz und Elend des letzten österreichischen Herrscherpaares, Wien-München 1976, S. 205.

3 Helmut Rumpler, Das Völkermanifest Kaiser Karls vom 16. Oktober 1918. Letzter Versuch zur Rettung des Habsburgerreiches, Wien 1966. 
Rumplers sollten bei einer wissenschaftlichen Beschäftigung mit dem Völkermanifest keinesfalls außer Acht gelassen werden. Rumpler sah das Völkermanifest zuletzt als „Panikaktion", die auf die Sicherung des Besitzstands Deutschösterreichs abzielte und die slawische Bevölkerung kompromittierte. ${ }^{4}$ Der Historiker und Archivar Peter Broucek behandelte ebenfalls das Manifest und dessen Entstehung im Rahmen seines Werks über Karl I. ${ }^{5}$ Broucek stellt es als eine wichtige Quelle zur Regierungszeit Karls und zu dessen politischen Entscheidungen im Allgemeinen dar. Dazu zählen ebenso die biographischen Werke des britischen Historikers Gordon Brook-Shepherd ${ }^{6}$ und die Studie des österreichischen Juristen Friedrich F. G. Kleinwaechter zur Entstehung der Republik Österreich. ${ }^{7}$ Bezüglich des Nationalitätenkonflikts ist der dritte Band des Sammelwerks „Die Habsburgermonarchie 1848-1918“ von Wandruszka/Urbanitsch zu erwähnen, in dem sich der österreichisch-US-amerikanische Jurist und Historiker Robert A. Kann genauer mit der Völkerproblematik auseinandersetzte. ${ }^{8}$ Er stellte dabei nicht primär die Frage, wie und ob der Konflikt zu lösen gewesen wäre, sondern untersuchte die Umstände, die zu den Diskrepanzen zwischen den Völkern führten und deren Ausgestaltung. In diesem Kontext ist ebenso der Beitrag des Wiener Historikers Lothar Höbelt im Sammelband „Die letzten Jahre der Donaumonarchie“ zu beachten. ${ }^{9}$ Für das Ende der Habsburgermonarchie und ihre Auflösung sind besonders auch die Arbeiten von Manfried Rauchensteiner erwähnenswert. ${ }^{10}$ Der Militärhistoriker legte eine nüchterne Analyse der Ereignisse am Ende der Donaumonarchie an den Tag.

Interessant ist zudem eine Publikation des Historikers und Archivars Rudolf Neck, in der Primärquellen in Form von Berichten und Dokumenten, die sich auch auf das Völkermanifest und das Ende der Monarchie beziehen, zu finden sind. ${ }^{11}$ Daraus lässt sich ein Eindruck des Stimmungsbilds während der letzten Wochen der Monarchie gewinnen. Die Kirchenhistorikerin Elisabeth Kovács setzte sich in ihrem mehrbändigen Werk „Untergang oder Rettung der Donaumonarchie?“ vor allem mit der Regierungszeit Karls I. und seinem vergeblichen Versuch, die Monarchie vor dem Untergang zu bewahren, auseinander. Sie kritisierte dabei Helmut Rumplers Thesen bezüglich des Ursprungs und

4 Helmut Rumpler, Kaiser Karl, die Friedensprojekte und das deutsch-österreichische Bündnis, in: Karl I. (IV.), der Erste Weltkrieg und das Ende der Donaumonarchie (Publikationen des historischen Instituts beim Österreichischen Kulturforum in Rom 14), hrsg. v. Andreas Gottsmann, Wien 2007, S. 13-22.

5 Peter Broucek, Karl I. (IV.). Der politische Weg des letzten Herrschers der Donaumonarchie, Wien-KölnWeimar 1997.

6 Brook-Shepherd, Karl I. bzw. Ders., Um Krone und Reich. Die Tragödie des letzten Habsburgerkaisers, Wien 1968.

7 Friedrich G. F. Kleinwaechter, Von Schönbrunn bis St. Germain. Die Entstehung der Republik Österreich, Graz-Wien-Köln 1964.

8 Robert A. Kann, Zur Problematik der Nationalitätenfrage in der Habsburgermonarchie 1848-1918, in: Die Völker des Reiches, 2. Teilb., hrsg. v. Adam Wandruszka, Peter Urbanitsch (Die Habsburgermonarchie 1848-1918 III), Wien 1980, S. 1304-1338.

9 Lothar Höbelt, Wohltemperierte Unzufriedenheit. Österreichische Innenpolitik 1908-1918, in: Die letzten Jahre der Donaumonarchie. Der erste Vielvölkerstaat im Europa des frühen 20. Jahrhunderts, hrsg. v. Mark Cornwall, o. O. 2006, S. 58-84.

10 Manfried Rauchensteiner, „Das neue Jahr machte bei uns einen traurigen Einzug”. Das Ende des Großen Krieges, in: ... der Rest ist Österreich (Das Werden der Ersten Republik I), hrsg. v. Helmut Konrad/ Wolfgang Maderthaner, Wien 2008, S. 21-44. bzw. Ders., Der Erste Weltkrieg und das Ende der Habsburgermonarchie 1914-1918, Wien-Köln-Weimar 2013.

11 Rudolf Neck, Österreich im Jahre 1918. Berichte und Dokumente, München 1968. 
der Hintergründe des Manifests. ${ }^{12}$ Die Publikationen von Andreas Bachleitner und Andrea Seidler ${ }^{13}$ - beide im Bereich der Sprach- und Literaturwissenschaft tätig - sowie jene der Historikerin Petronilla Ehrenpreis ${ }^{14}$ bieten einen Überblick über die Medienlandschaft Cisleithaniens ${ }^{15}$ und können bei der Analyse der Reaktionen der deutschsprachigen Presse auf das Völkermanifest herangezogen werden.

\section{Konzeption und Methodik}

Im Hauptteil werden die Hintergründe, die zum Erlass des Manifests beigetragen haben, dargelegt. Die Völkerproblematik des Habsburgerreiches steht dabei zunächst im Vordergrund. Der Charakter des Nationalitätenkonflikts und dessen Ausgestaltung, auch in Bezug auf den Ersten Weltkrieg, werden ausführlich erläutert. Anschließend werden drei Ereignisse, die jeweils einen entscheidenden Beitrag zur Zuspitzung der Situation leisteten, erörtert. Es handelt sich dabei um die "Sixtus-Affäre“ vom April 1918, die Anerkennung des Rechts auf Unabhängigkeit der Tschechen und Slowaken im Sommer 1918, sowie den Zusammenbruch Bulgariens im September desselben Jahres.

Darauf folgt ein Kapitel, das sich mit der genaueren Entstehung des Völkermanifests als Dokument an sich beschäftigt. Neben der Analyse der persönlichen Initiative Kaiser Karls I. ist ein Überblick über die Pläne für eine Verfassungsreform der österreichischen Reichshälfte sowie der Föderalisierungsbestrebungen von 1914 bis 1918 gegeben. Eine wichtige Rolle nahm dabei das Ministerium Hussarek ein. Die Bedeutung von Max Hussarek-Henlein (1865-1935) - Ministerpräsident vom 27. Juli bis 28. Oktober 1918 - im Kontext der Entstehung des Völkermanifests wird deshalb in diesem Teil genauer behandelt.

Darauf folgend werden die Reaktionen auf den Manifest-Erlass seitens der deutschsprachigen Presse Cisleithaniens, der Politik, und - in geringem Ausmaß - auch der Bevölkerung geschildert. In einem abschließenden Kapitel werden bedeutende Bewertungen und Einschätzungen des Manifests aus der Forschung gegenübergestellt und diskutiert. Nach der Überprüfung der zentralen Hypothese dieser Arbeit folgt auch eine Einschätzung des Autors. Zuletzt wird ein Fazit gezogen, in dem die Fragestellungen und die Hypothese noch einmal aufgegriffen werden und eine Zusammenfassung der Erkenntnisse gegeben ist.

Hinsichtlich der Methodik ist zu erwähnen, dass neben der Sekundärliteratur vor allem das Völkermanifest als Dokument selbst die zentrale Quelle dieser Arbeit darstellt. Daneben werden im Kapitel, das von den Reaktionen auf das Manifest handelt, zeitgenössische

12 Elisabeth Kovács, Untergang oder Rettung der Donaumonarchie? Die österreichische Frage. Kaiser und König Karl I. (IV.) und die Neuordnung Mitteleuropas (1916-1922), Bd. 1, Wien-Köln-Weimar 2004.

13 Norbert Bachleitner/Andrea Seidler, Zur Medialisierung gesellschaftlicher Kommunikation in Österreich und Ungarn. Studien zur Presse im 18. und 19. Jahrhundert (Finno-Ugrian Studies in Austria 4), Wien 2007.

14 Petronilla Ehrenpreis, Die reichsweite Presse in der Habsburgermonarchie, in: Politische Öffentlichkeit und Zivilgesellschaft. Die Presse als Faktor der politischen Mobilisierung, hrsg. v. Helmut Rumpler/Peter Urbanitsch (Die Habsburgermonarchie 1848-1918), Wien 2006, S. 1715-1818.

15 Als "Cisleithanien“ wurde die österreichische Reichshälfte nach dem "Ausgleich" mit Ungarn von 1867 bezeichnet. 
Zeitungsartikel - einsehbar in der Datenbank ANNO ${ }^{16}$ - verwendet. Diese stammen aus ausgewählten deutschsprachigen Tageszeitungen Cisleithaniens, die verschiedene politische Richtungen repräsentieren. Darüber hinaus wird ein Bericht der Wiener Polizeidirektion vom 18. Oktober 1918 als Primärquelle zu Rate gezogen. ${ }^{17}$

\section{Hintergründe}

\section{Völkerproblematik des Habsburgerreiches}

Der Nationalitätenkonflikt Österreich-Ungarns ist eines der interessantesten historischen Phänomene der österreichischen bzw. europäischen Geschichte, dessen Analyse sich allerdings äußert komplex gestaltet. Die ethnische Heterogenität der Monarchie stellte eine große Herausforderung für den inneren Zusammenhalt des Staatsgebildes dar. Keine der nationalen Gruppen bildete eine absolute Mehrheit innerhalb der Monarchie. Die "Alleinherrschaft des deutschen Zentralismus" war mit dem Ende des Neoabsolutismus, zehn Jahre nach der Revolution von 1848/49, Geschichte. Die politisch-kulturelle Führungsstellung der Deutschen blieb im Zeitraum 1848 bis 1918 zwar weitgehend aufrecht, geriet aber zunehmend ins Wanken. ${ }^{18}$ Von den elf wesentlichen nationalen Gruppen Österreich-Ungarns waren die sechs zahlreichsten ${ }^{19}$ - Deutsche ${ }^{20}$, Italiener, Polen, Rumänen, Ruthenen und Serben - nicht ausschließlich im Reichsgebiet ansässig. Die Mehrheit dieser Nationalitäten befand sich außerhalb der Donaumonarchie. Die übrigen fünf Nationalitäten - Kroaten, Magyaren, Slowaken, Slowenen und Tschechen waren im Wesentlichen in den Grenzen Österreich-Ungarns beheimatet, bildeten aber im nationalen Vergleich die Minderheit. ${ }^{21}$ Durch diese Konstellation wurde der Fortbestand der Monarchie auch in außenpolitischer Hinsicht bedroht, da der Einfluss auf die nationalen Gruppen von außen stets einen beachtlichen Faktor für die gesellschaftliche und politische Interaktion innerhalb der Monarchie darstellte. So leistete etwa das deutsch-österreichische Bündnis einen Beitrag zum Zerfall der Donaumonarchie. Es führte schlussendlich in den Ersten Weltkrieg und zur militärischen Niederlage sowie der damit verbundenen Auflösung Österreich-Ungarns. ${ }^{22}$ Robert A. Kann unterschied hinsichtlich des Nationalitätenproblems zwei Hauptgruppen: Auf der einen Seite standen jene, die nicht in erster Linie vom Nationalismus ${ }^{23}$ dirigiert wurden, sondern von einer

16 Homepage ANNO, [http://anno.onb.ac.at], eingesehen 04.03.2015.

17 Siehe Neck, Österreich, 1968.

18 Kann, Nationalitätenfrage, S. 1310.

19 Sie bildeten ca. drei Fünftel der Gesamtbevölkerung, während die Kroaten, Magyaren, Slowaken, Slowenen und Tschechen zwei Fünftel darstellten. Beruhend auf Volkszählungen kann für das Jahr 1910 von folgenden Bevölkerungsanteilen ausgegangen werden: 23,9\% Deutsche, 20,2\% Magyaren. Die anderen Nationalitäten umfassten jeweils weniger als die Hälfte des Anteils der Deutschen, siehe Kann, Anmerkung 7, S. 1310.

20 Die Deutschösterreicher werden hier nach Kann in ihrem ethnischen Kontext als Deutsche klassifiziert.

21 Kann, Nationalitätenfrage, S. 1311.

22 Ebd., S. 1336

23 Nationalismus definiert Kann folgendermaßen: Nationalismus bedeutet, die Forderungen eines „Volksstamms" zu vertreten. Dies kann mit einem höheren oder geringeren Grad an Radikalismus und an Anpassungsfähigkeit an politische Gegebenheiten geschehen. Bei dem dazugehörigen nationalistischen Programm wird keine Rücksicht darauf genommen, ob es im Sinne eines übernationalen Gleich- 
politischen Parteibildung, die alle politischen Richtungen abdeckte und nicht unbedingt national ausgerichtet sein musste. ${ }^{24}$ Auf der anderen Seite gab es die, bei denen der Nationalismus in ethnischer wie staatsrechtlicher Hinsicht das parteipolitische Denken und Agieren dominierte. ${ }^{25}$ Überdies kam Kann zum Schluss, dass das Nationalbewusstsein - und das Streben danach - stieg, je vollständiger das politische Spektrum innerhalb einer Nationalität repräsentiert war, und je besser soziale Konflikte innerhalb einer ethnischen Gruppe gelöst werden konnten. ${ }^{26}$

Laut Peter Broucek war den Völkern Österreich-Ungarns „der Gedanke einer Loslösung vom Hause Österreich [...] bis in den Weltkrieg hinein fremd“. ${ }^{27}$ Es ging nicht gegen die Habsburger als übergeordnete Herrscherfamilie. Es ging um das Streben nach kultureller Identität - Schlüsselelemente waren dabei die Sprache und die Religion - sowie nach Autonomie und Mitbestimmung im Staat. Sprachliche Konflikte entstanden bei der Organisation von öffentlichen Einrichtungen wie Schulen, Universitäten, Ämtern und Gerichten, aber auch im Bereich der Medien, der Industrie sowie in Handel und Gewerbe. Als verbindendes Element zwischen den Völkern trat der Katholizismus als Religion der Mehrheit auf und stärkte auch die Bindung zum habsburgischen Kaiserhaus. ${ }^{28}$

1867 kam es zum verfassungsrechtlichen „Ausgleich“ mit Ungarn. Aus dem Kaisertum Österreich wurde die Österreichisch-Ungarische Doppelmonarchie, die fortan aus zwei separaten Reichshälften bestehen sollte. Deren Grenzen wurden ungeachtet der ethnischen Gegebenheiten gezogen. Die Reichsteile sollten außerdem nur mehr im finanziellen, militärischen und außenpolitischen Bereich zusammenarbeiten. Die österreichische Reichshälfte (Cisleithanien) bestand aus den „im Reichsrat vertretenen Königreichen und Ländern“. Die ungarische (Transleithanien) aus den „Ländern der Heiligen Ungarischen Krone“. Beide Reichshälften erhielten eine zentralistische Verfassung. ${ }^{29}$

Die slawische Bevölkerung fühlte sich nach dem Ausgleich übergangen und zurückgewiesen. Tatsächlich sahen führende slawische Politiker nach dem verlorenen Krieg von 1866 andere Pläne für die Zukunft der Monarchie vor: Es sollte zur Bildung einer österreichischen, ungarischen, böhmischen und polnischen "Ländergruppe" kommen. Die ungarische Seite nahm ihrerseits gesonderte Verhandlungen auf und berief sich auf die Verfassung. Sie konnte sich schließlich gegenüber den slawischen Föderalismusbestrebungen durchsetzen - nicht zuletzt aufgrund der Angst der Deutschliberalen vor "den Slawen“ und des Einsatzes der Kaiserin Elisabeth (1837-1898), für "ihre“ Ungarn. Von da an kam es zum berechtigten Vorwurf der übrigen Völker, vor allem der slawischen Bevölkerung, dass sie von deutschen und magyarischen Kräften zu

heitsprinzips - gleiche Rechte für alle Völker - durchführbar ist. Demnach entwickelten die einzelnen nationalen Gruppen eigene Programme, die kaum Rücksicht auf die Durchführbarkeit in einem supranationalen Gebilde wie der Habsburgermonarchie nahmen und deshalb auch nicht auf staatlichem Wege durchführbar erschienen, siehe Kann, Nationalitätenfrage, S. 1308.

24 Hierzu zählt Kann Deutschösterreicher, Italiener, Polen, Slowenen und Tschechen.

25 Hierzu zählt Kann Kroaten, Magyaren, Rumänen, Ruthenen, Serben, Slowaken.

26 Kann, Nationalitätenfrage, S. 1330.

27 Broucek, Karl I. (IV.), S. 168.

28 Ebd., S. 168

29 Ebd., S. 166-67. 
„Nationen zweiter Klasse“ herabgesetzt wurden. Dieses Gefühl der Unterlegenheit wurde durch Sprachverordnungen wie die ungarischen Schulgesetze 1879 bis 1883, die die „Kenntnis [...] und Pflege der magyarischen Sprache für Lehrer und Schüler“ verordneten, verstärkt. ${ }^{30}$

Von einem „Völkerkerker“31 kann laut Hanna Domandl aber nur bezüglich der ungarischen Reichshälfte gesprochen werden. Während die nationalen Gruppen in Cisleithanien relativ frei agieren konnten, hätten die Ungarn versucht, die Nichtmagyaren ihrer "Nationalität zu entfremden“. ${ }^{32}$ Dazu muss erwähnt werden, dass es in der Verfassung der österreichischen Reichshälfte den Artikel 19 gab, laut dem jedem „Volksstamm ein unverletzliches Recht auf Wahrung und Pflege seiner Nationalität und Sprache“ zustand. ${ }^{33}$ Eine politische Mitbestimmung war jedoch nie Thema. Die magyarische Assimilationspolitik in der anderen Reichsseite trug sicherlich einiges dazu bei, dass sich die Nationalitätenfrage immer weiter zuspitzte, stellte aber nicht den Hauptgrund dafür dar.

Die größten Konfliktlinien ergaben sich zwischen tschechischer und deutschböhmischer sowie zwischen ungarischer bzw. deutschösterreichischer und südslawischer Bevölkerung, die sich zudem noch untereinander nicht einig war. ${ }^{34}$ Ein Schlüsselereignis für die tschechische Volksgruppe stellte die gescheiterte Anerkennung des Böhmischen Staatsrechts 1871 dar, die für die Monarchie den Trialismus ${ }^{35}$ bedeutet hätte und beinahe geglückt wäre. Während über eine Verfassung verhandelt wurde, hatte Kaiser Franz Joseph bereits sein Einverständnis zu einer Krönung in Prag gegeben. Durch Intervention der Deutschböhmen im Landtag und Reichsrat, der Ungarn, und auch durch Druck seitens des Deutschen Reiches wurde der Plan jedoch nicht in die Tat umgesetzt. Daraufhin trat die Bewegung der „Jungtschechen“36 auf den Plan, die radikalere Forderungen repräsentierten. ${ }^{37}$ Den Gipfel der deutsch-tschechischen Differenzen machte Broucek an der Sprachverordnung der Regierung unter Kasimir Graf Badeni (1846-1909) von 1897 fest. Nach ihr hätten Staatsbeamte - auch für den „inneren Dienstverkehr“ - die deutsche und die tschechische Sprache beherrschen müssen. Bei den meisten Tschechinnen und Tschechen war dies ohnehin schon der Fall. Bei der Mehrheit der deutschböhmischen Bevölkerung jedoch nicht. Nach schweren Protesten, auch seitens übriger deutschösterreichischer Einwohnerinnen und Einwohner Österreich-Ungarns, musste die Verordnung aufgehoben werden und Badeni zurücktreten. ${ }^{38}$

30 Broucek, Karl I. (IV.), S. 166-168

31 Hanna Domandl, Kulturgeschichte Österreichs. Von den Anfängen bis 1938, Wien 1992, S. 368.

32 Ebd., S. 368-369.

33 Broucek, Karl I. (IV.), S. 167.

34 Ebd., S. 169.

35 Unter dem Trialismus wurde die verfassungsrechtliche Dreiteilung der Habsburgermonarchie verstanden. Neben einer österreichischen und ungarischen Reichshälfte, welche nach dem Ausgleich von 1867 in Form des Dualismus bereits vorlagen, sollte ein entsprechender slawischer Reichsteil eingerichtet werden.

36 Die „Jungtschechen“ entwickelten sich aus der Partei der „Alttschechen“, der Národní strana (National partei), und nannten sich Národní strana svobodomyslná (Freisinnige Nationalpartei). Zunächst war die jungtschechische Partei gesellschaftlich heterogen, repräsentierte aber zunehmend das tschechische Besitz- und Bildungsbürgertum, siehe dazu genauer Jiři Kořalka, R. J. Crampton, Die Tschechen, in: Die Völker des Reiches, 1. Teilb., hrsg. v. Adam Wandruszka/Peter Urbanitsch (Die Habsburgermonarchie 1848-1918 III), Wien 1980, S. 489-521, hier S. 513-514.

37 Broucek, Karl I. (IV.), S. 169.

38 Ebd., S. 169-170. 
Auch unter den übrigen Volksgruppen regte sich die Unzufriedenheit mit den staatsrechtlichen Gegebenheiten. Die slowakische Bevölkerung strebte unter der ungarischen Bevormundung nach Anerkennung, näherte sich aber laut Broucek erst im Ersten Weltkrieg der tschechischen an. Während die Polinnen und Polen in Galizien auf die "Wiederherstellung ihres Staates" hofften, strebte die ebenfalls in diesem Raum ansässige ruthenische Population zunehmend nach Autonomie. ${ }^{39}$ Die Rumäninnen und Rumänen in Siebenbürgen und im Banat, die von ihren Landsleuten im Königreich Rumänien getrennt waren, zeigten lange Zeit keine separatistischen Bestrebungen. Grund dafür war die Rolle Österreich-Ungarns in der Politik des Königreichs Rumänien. Die Habsburgermonarchie wurde als Schutzschild gegen den Zarismus angesehen. Laut Broucek waren die Italienerinnen und Italiener in Tirol, im Küstenland und in Dalmatien die einzigen, bei denen ansatzweise ein echter Separatismus feststellbar war. Konflikte auf sprachlicher Ebene gab es für die italienische Bevölkerung vor allem mit Angehörigen der südslawischen Volkgruppenen. ${ }^{40}$

Die scheinbare Unlösbarkeit der Völkerproblematik Österreich-Ungarns, aber auch der verlorene Weltkrieg, führten schließlich im Herbst 1918 zum Zerfall. Das Völkermanifest kann in diesem Zusammenhang als ein später Lösungsversuch gesehen werden, der nicht den gewünschten Erfolg brachte. Die genauen Hintergründe werden dabei noch zu klären sein.

Vor dem Weltkrieg sei Österreich ein „Demerkenswert liberales Reich gewesen, das viele Freiräume bot", schrieb Lothar Hobelt."1 Vor 1914 hätten sich dynastischer Patriotismus und ethnischer Nationalismus lange Zeit die Waagschale gehalten und gegenseitig neutralisiert. Mit dem Krieg änderten sich aber, durch Reglementierungen in allen Bereichen und die verstärkte staatliche Aktivität, die Umstände. Die Bürokratie wurde dermaßen intensiviert, dass sie alle Dimensionen des Alltags tangierte und den Nährboden für neue, folgenschwere ethnische Konflikte bot: „Der Krieg brachte eine zentralisierende Dynamik mit sich, die in einem Vielvölkerstaat nicht ohne Rückwirkungen auf das Verhältnis Untereinander bleiben konnte"42.

\section{Drei entscheidende Ereignisse}

\section{Die "Sixtus-Affäre" - Ottokar Czernin (1872-1932) gegen Karl I.}

Die im Nachhinein als „Sixtus-Affäre“ bezeichnete politische Krise rund um heimliche Friedensverhandlungen Österreich-Ungarns mit Frankreich wurde durch eine Rede Ottokar Czernins (1872-1932), Minister des Äußeren, am 2. April 1918 verursacht. Er sprach darin zunächst über den Friedensschluss mit Russland im Osten und die Vorteile,

39 Die Alt-Ruthenen, die als österreichfreundlich galten, wurden von den Jung-Ruthenen abgelöst. Diese Bewegung war zunehmend anti-österreichisch und pro ukrainisch eingestellt. Galizien wurde als „Piemont des Ukrainertums" angesehen, siehe Broucek, S. 168.

40 Broucek, Karl I. (IV.), S. 168-169.

41 Höbelt, Wohltemperierte Unzufriedenheit, S. 83.

42 Ebd., S. 83. 
die sich daraus ergeben würden. Außerdem betonte er in diesem Zusammenhang die Wichtigkeit des Bündnisses zwischen Österreich und Deutschland und die Bündnistreue Kaiser Karls I. ${ }^{43}$ Dann kam er auf den westlichen Kriegsschauplatz zu sprechen. Konkret ging es um Friedensverhandlungen zwischen Österreich-Ungarn und Frankreich, die, so Czernin, vom französischen Ministerpräsidenten Georges Clemenceau (1841-1929) ausgegangen waren und daran scheiterten, dass Frankreich nicht bereit gewesen war, über die Forderung Elsass-Lothringens zu sprechen und womöglich darauf zu verzichten. ${ }^{44}$ Georges Clemenceau wurde damit als eigentlicher Friedensverhinderer dargestellt, der von seinen Positionen nicht abrücken und dem friedenswilligen ÖsterreichUngarn nicht entgegenkommen wollte. In weiterer Konsequenz sei Clemenceau sogar ein „Kriegsverlängerer". ${ }^{45}$ Clemenceau dementierte diese Vorwürfe und veröffentlichte seinerseits den Sixtusbrief, von dem Czernin keine Kenntnis hatte. Damit lieferte er nachhaltige Beweise, dass es gerade umgekehrt gewesen war und dass die Friedensverhandlungen von Österreich-Ungarn und nicht von Frankreich ausgegangen waren. Kaiser Karl hatte bereits im März 1917 versucht, Friedenssondierungen vorzunehmen. Durch die Mithilfe seines Schwagers Sixtus von Bourbon-Parma (1886-1934) sollte der österreichische Wille zum Frieden und die Bereitschaft, mit Frankreich zu verhandeln, zum Ausdruck gebracht werden. Es handelte sich dabei um Geheimverhandlungen, deshalb war in der Öffentlichkeit davon nichts bekannt geworden und auch in Regierungskreisen hatte kaum jemand Bescheid gewusst. ${ }^{46}$

In jedem Fall brachten die Enthüllungen Clemenceaus Kaiser Karl in arge Bedrängnis gegenüber dem deutschen Verbündeten. Denn die Sixtus-Aktion bedeutete nichts anderes, als dass Österreich-Ungarn hinter dem Rücken Deutschlands über einen Separatfrieden mit Frankreich verhandelte. Deshalb leugnete Karl auch die Existenz des Sixtusbriefes und bezichtigte Clemenceau in einer öffentlichen Erklärung, die Unwahrheit zu sagen. Czernin, der den Kaiser wiederholt kritisierte, trat schließlich am 14. April 1918 als Minister des Äußeren zurück. Kaiser Karl begab sich daraufhin mit Czernins Nachfolger Stephan Burian von Rajecz (1852-1922) ins Hauptquartier der deutschen Obersten Heeresleitung in die belgische Stadt Spa. Vielfach wurde dies als „Canossagang“ Karls gewertet, vor allem von internationaler Seite. In der Folge kam es im Vertrag von Spa zu einem erneuerten "Schutz- und Trutzbündnis" zwischen Wien und Berlin. Helmut Rumpler sah darin „[...] nichts weniger als die Kapitulation Österreichs vor Deutschland“. ${ }^{47}$ Damit ist gemeint, dass sich Österreich-Ungarn von da an in völlige Abhängigkeit von Deutschland begab. Vor allem was die militärischen Aktionen betraf, konnte es nicht mehr eigenständig agieren. Es trat jenes Szenario ein, das Kaiser Karl unbedingt hatte verhindern wollen - nämlich ein "größeres Bayern“48 zu werden, und in den außenpolitischen Entscheidungen ganz

43 Elisabeth Kovács, Untergang oder Rettung der Donaumonarchie, Bd. 1, S. 394.

44 Rauchensteiner, Ende des Großen Krieges, S. 30.

45 Rumpler, Friedensprojekte, S. 20.

46 Rauchensteiner, Ende des Großen Krieges, S. 30.

47 Rumpler, Friedensprojekte, S. 20-21.

48 Diese Befürchtung hatte Karl schon 1914 artikuliert. Notizen Karls vom 24. 12. 1914, zit. n. Peter Broucek, Karl I. (IV.). Der politische Weg des letzten Herrschers der Donaumonarchie, Wien-Köln-Weimar 1991, S. 85 . 
und gar von Berlin abhängig zu sein. Aus diesem Grund hatte er mit der "Sixtus-Mission” im März 1917 versucht, sich durch eigenständige Friedensverhandlungen und einen möglichen Separatfrieden dem deutschen Einfluss zu entziehen.

Die "Sixtus-Affäre“ schlug in der nationalen und internationalen Presse hohe Wellen. Sie beeinträchtigte die Glaubwürdigkeit und das Ansehen Kaiser Karls schwer und machte die Chancen auf einen raschen Frieden zunichte. Denn der Kaiser baute, so der britische Historiker Gordon Brook-Shepherd, seine "gesamte Friedensdiplomatie auf die Integrität seiner eigenen Person und auf das Prestige der Dynastie" auf. ${ }^{49}$ Karl wurde vor allem von deutschnationalen Kreisen aufs Heftigste kritisiert. Es herrschte ein Gefühl der Unsicherheit, auch unter jenen, die mit der „Deutschtümelei“ wenig am Hut hatten: „Es schien keine Alternative zum , deutschen Kurs’ zu geben, solange die einzige Chance für das Überleben der Monarchie ein militärischer Sieg war. “50 Deshalb waren viele bereit, eine Schmälerung der eigenen Selbständigkeit durch die deutsche Bevormundung in Kauf zu nehmen. ${ }^{51}$ Laut Manfried Rauchensteiner avancierte Czernin im Nachhinein zur "Galionsfigur der Deutsch-Österreicher“. Es gab zeitweise sogar Bestrebungen, den Kaiser zur Abdankung zu bewegen, die aber schlussendlich nicht realisiert wurden. ${ }^{52}$

Der US-amerikanische Außenminister Robert Lansing (1864-1928) brachte einen Tag nach der Publikation des "Sixtusbriefs" die zu erwartenden politischen und militärischen Folgen der "Sixtus-Affäre“ in einem Statement auf den Punkt:

„Die Aktion Mr. Clemenceaus zum Brief Kaiser Karls an Prinz Sixtus von Bourbon Parma [...] ist meiner Meinung nach ein Stück der erstaunlichsten Dummheit, wofür man keine befriedigende Entschuldigung vorbringen kann. Dachte Clemenceau, Graf Czernin als Lügner zu überführen, hatte er wahrscheinlich Erfolg, aber zu welchem Preis! Seine Enthüllung hat Österreich vollständig (mit Haut und Haaren) in die Arme Deutschlands getrieben. Der Kaiser von Österreich hat nun keine andere Wahl, als zu schweigen (,to eat his words') und in eindeutigster Formulierung seine Loyalität gegenüber seinem dominierenden Verbündeten und dessen Zielen zu bekräftigen. Sogar wenn Karl anders handeln wollte, verhindert das die Dummheit Clemenceaus und die Angst vor Deutschland. [...] Es gab immer die Möglichkeit von Ergebnissen, die aus dem evidenten Wunsch des österreichischen Kaisers nach Frieden um jeden Preis resultierten. Diese Möglichkeit hat die Narretei Clemenceaus vernichtet. [...] Alles was wir getan haben, ist umsonst. Wir können alle inoffiziellen Konferenzen, die wir hatten, vergessen. “53

Hier wird klar ersichtlich, dass die wichtigste Forderung in allen Friedensverhandlungen der Entente die Auflösung des deutsch-österreichischen Bündnisses darstellte. Laut Rumpler war dies sogar "das zentrale Kriegsziel schlechthin“54. Dass Lansing derart auf

49 Brook-Shepherd, Karl I. S. 185.

50 Höbelt, Wohltemperierte Unzufriedenheit, S. 82.

51 Ebd.

52 Rauchensteiner, Ende des Großen Krieges, S. 30.

53 Zit. n. Kovács, Untergang oder Rettung, Bd. 1, S. 407-408.

54 Rumpler, Friedensprojekte, S. 21. 
die Vorgehensweise Clemenceaus reagierte, bestätigt dies. Rumpler meinte aber weiter, dass Clemenceau die Abhängigkeit Österreich-Ungarns von Deutschland habe aufzeigen wollen, um seine Verbündeten zu überzeugen, den Krieg bis zum Ende weiterzuführen. Denn ein Fortbestand Österreich-Ungarns, der bei einem möglichen Separatfrieden noch am ehesten zu erwarten gewesen wäre, war nach der Auffassung Clemenceaus nicht mehr notwendig, da die Habsburgermonarchie „ihrer alten Funktion als Gegengewicht gegen Deutschland und Russland nicht mehr entsprach“55.

Der Vertrag von Spa zwischen Österreich-Ungarn und dem Deutschen Reich, der aus der "Sixtus-Affäre" resultierte, hatte auch maßgebliche Auswirkungen auf die innenpolitische Situation in der Donaumonarchie. Denn er brachte nichts anderes als einen Sieg der "großdeutschen Sache" zum Ausdruck, der die nichtdeutsche - allen voran die slawische - Bevölkerung verunsicherte. Auch hatte Czernin in seiner Rede vom 2. April, betitelt mit „Über den Frieden und gegen czechische Verräter", den Unmut der Tschechen geschürt. Tschechische Abgeordnete erklärten daraufhin ihr Streben nach einem unabhängigen tschechisch-slowakischen Staat. ${ }^{56}$ Die "Sixtus-Affäre“ hatte damit auch zu einer Zuspitzung des Völkerproblems beigetragen.

Folgt man Gordon Brook-Shepherd, so waren es aber vor allem zwei weitere Ereignisse, die den endgültigen Zusammenbruch des Vielvölkerstaates einläuteten. Sie werden nun im Folgenden skizziert.

\section{Die Anerkennung des Rechts auf Unabhängigkeit der Tschechen und Slowaken}

Am 29. Juni 1918 wurde ein von emigrierten Tschechoslowaken konstituierter Nationalrat, der sich in Paris befand, von Frankreich offiziell als Vorgänger der möglichen Regierung eines selbständigen tschechoslowakischen Staates anerkannt. Damit wurde auch das Recht auf die Unabhängigkeit der Tschechoslowaken bestätigt. ${ }^{57}$ Dies geschah mittels der Note des französischen Außenministers Stephen Pichon (1857-1933) an Edvard Beneš (1884-1948), damals Generalsekretär des "Tschechischen Nationalrats“. Beneš hatte schon im April 1918 an einem Kongress der "unterdrückten Völkerschaften“ Österreich-Ungarns in Rom teilgenommen. In Anwesenheit von Vertretern Frankreichs, Großbritanniens und der USA wurde von Repräsentanten der italienischen, polnischen, tschechischen und südslawischen Bevölkerung die „volle Unabhängigkeit und uneingeschränktes Recht auf Vereinigung" festgestellt. ${ }^{58}$

Die Entscheidung Frankreichs zur Anerkennung der Tschechoslowakei wurde von mehreren Faktoren beeinflusst. Einerseits spielte dabei das 14-Punkte-Programm des US-amerikanischen Präsidenten Thomas Woodrow Wilson (1856-1924), das dieser am 8. Januar 1918 verkündete, eine große Rolle. Sein Friedensplan enthielt als zehnten Punkt die Zusicherung einer „autonomen Entwicklung” für alle Völker Österreich-

55 Rumpler, Friedensprojekte, S. 21

56 Brook-Shepherd, Karl I., S. 196.

57 Ebd., S. 194

58 Reinhold Lorenz, Kaiser Karl und der Untergang der Donaumonarchie, Graz-Wien-Köln 1959, S. 480-481. 
Ungarns. ${ }^{59}$ Des Weiteren begannen die Entente-Mächte, allen voran die Briten, die Propaganda gegenüber Österreich-Ungarn zu verschärfen. An der italienischen Front wurden etwa Flugblätter abgeworfen, in denen den einzelnen Ethnien ihr Recht auf unabhängige Staaten zugesprochen wurde. Das verfolgte Ziel war dabei die Aushöhlung der habsburgischen Autorität, vor allem auf militärischer Ebene. In der Folge gewannen politisch agierende Emigranten, die sich gegen die Habsburgermonarchie positionierten, an Einfluss. ${ }^{60}$

Jedenfalls wurde durch den Akt der Anerkennung der tschechoslowakischen Unabhängigkeitsbestrebungen durch Frankreich ein Prozess in Gang gesetzt, der nicht mehr aufzuhalten war. ${ }^{61}$ Auf die französische Note folgten bald darauf entsprechende Erklärungen Großbritanniens und der Vereinigten Staaten. ${ }^{62}$ In diesem Zusammenhang kommt der "Sixtus-Affäre“ ebenfalls eine Bedeutung zu, denn nachdem Kaiser Karl seinen deutschen Verbündeten abermals die Treue aussprach, und klar war, dass dieses Bündnis nicht zu sprengen war, fiel es den Alliierten erheblich leichter, die tschechoslowakischen Exilpolitiker und deren Forderungen anzuerkennen. ${ }^{63}$

Am 14. August 1918 ging Großbritannien noch einen Schritt weiter und gestand der Tschechoslowakei den Status einer „alliierten Nation“ zu. Gleichzeitig wurden auch diejenigen Tschechen und Slowaken, die in der sogenannten "Tschechischen Legion“64 gegen die Mittelmächte kämpften, als reguläre Streitkräfte neben denen der Entente anerkannt. ${ }^{65}$ Österreich-Ungarn protestierte vehement gegen diesen Schritt und wandte ein, dass der "Tschechische Nationalrat" in Paris als ein „Komitee von Privatpersonen" anzusehen sei. Auch der Status als eigene kriegführende Macht wurde negiert und darauf hingewiesen, dass alle Beteiligten, bei denen es sich um reguläre österreichische oder ungarische Staatsbürger handelte, als Hochverräter anzusehen seien und dies auch von ihren Landsleuten so gesehen werde. ${ }^{66}$ Diese Stellungnahme wurde offenbar nicht mehr ernst genommen und verfehlte ihr Ziel. Kurz darauf bestätigten die USA den Status der Tschechoslowakei als offizielle, aufseiten der Alliierten kämpfende Macht. ${ }^{67}$ Nach Gordon Brook-Shepherd waren damit mögliche Verhandlungen zwischen Karl I. und USPräsident Wilson gescheitert, bevor diese auch nur beginnen konnten. Karl wurde von den Vereinigten Staaten in der Folgezeit als "lästiger Eigentümer eines großen Gebäudes, das nun in einzelne Wohnungen aufgeteilt und dessen Bewohnern übergeben werden soll“ angesehen, und nicht mehr als Kaiser Österreich-Ungarns wahrgenommen. ${ }^{68}$

59 Das lebendige Museum Online (Lemo), Das 14-Punkte-Programm, O. D., [http://www.dhm.de/lemo/ hatml /dokumente/14punkte/], eingesehen 25.04.2014.

60 Brook-Shepherd, Karl I., S. 197.

61 Ebd.

62 Lorenz, Kaiser Karl, S. 481.

63 Rumpler, Friedensprojekte, S. 21.

64 Kriegsgefangene, die den Alliierten in die Hände gefallen waren, wurden gezielt angeworben, um in der "Tschechischen Legion", auch „Tschechoslowakische Legion” genannt, gegen die Mittelmächte zu kämpfen.

65 Brook-Shepherd, Karl I., S. 197

66 Lorenz, Kaiser Karl, S. 482.

67 Brook-Shepherd, Karl I., S. 198

68 Ebd. 
Die Auflösung der Habsburgermonarchie fand also auf dem Papier bereits frühzeitig statt, denn die Entente konzentrierte sich nun auf eine Vorbereitung der späteren Aufteilung des Vielvölkerreiches und zog einen Verhandlungsfrieden, nach dem sich die Monarchie noch selbst durch innere Reformen hätte retten können, nicht mehr in Betracht. ${ }^{69}$

In jedem Fall stand Kaiser Karl durch die Anerkennung der Tschechoslowakei unter massivem politischem Druck. Spätestens zu diesem Zeitpunkt hätte er Maßnahmen setzen müssen, um die Unabhängigkeitsbestrebungen der Tschechoslowaken und anderer nationaler Gruppen, die sich in der Monarchie befanden, vonseiten des Staates zu lösen.

\section{Der Zusammenbruch Bulgariens im September 1918}

Bulgarien war 1915 an der Seite der Mittelmächte in den Krieg eingetreten und nahm als Bündnispartner vor allem für Österreich-Ungarn durch die strategisch bedeutsame Lage an der Südostflanke der Monarchie einen wichtigen Platz ein. Als am 25. September 1918 die Meldung vom Zusammenbruch Bulgariens nach Wien gelangte, war Kaiser Karl laut Brook-Shepherd alles andere als überrascht. Er hatte dieses Szenario schon lange kommen sehen und deshalb die deutschen Verbündeten dazu aufgefordert, weitere Truppen an die Südostfront zu verlegen. Er wurde stets abgewimmelt und nicht ernst genommen, auch mit der Begründung, dass Ferdinand I. von Bulgarien (1861-1948), der aus der Dynastie Sachsen-Coburg-Kohary stammte und in Bulgarien den Zarentitel angenommen hatte, seinen Bündnispartnern treu bleiben und bis zuletzt durchhalten würde. ${ }^{70}$ Der Angriff der alliierten Truppen an der Südostfront, bestehend aus französischen, serbischen, britischen und italienischen Verbänden, begann am 14. September 1918. Schon nach drei Tagen zeigten sich bei den bulgarischen Divisionen Auflösungserscheinungen, womit der Abwehrkampf den vorhandenen österreichisch-ungarischen und deutschen Truppen vorbehalten blieb. ${ }^{71}$

Laut Manfried Rauchensteiner wurde der bevorstehende Zusammenbruch Bulgariens in den Zeitungen der österreichisch-ungarischen Monarchie zunächst konsequent verschwiegen. Dass die Zufuhr von weiteren Truppen ausblieb, wurde mit „schlechten Straßenverhältnissen" erklärt. ${ }^{72}$ Damit sollte kaschiert werden, dass es - vor allem aus logistischen Gründen - nicht möglich war, in dieser kurzen Zeit Truppen an die Balkanfront zu verschieben, weil die dazu notwendigen Eisenbahn-Züge gar nicht zur Verfügung standen. Als die Niederlage feststand, ergriff Ferdinand I. die Flucht und dankte ab. Ursprünglich plante er, nach Österreich zu flüchten, da er in der Nähe Wiens ein Anwesen besaß. Kaiser Karl wollte einen solchen „zweifelhaften Verbündeten“ jedoch nicht aufnehmen und ließ Ferdinand ausrichten, er sei unerwünscht. Trotz Protests war Ferdinand schließlich gezwungen, weiterzufahren. ${ }^{73}$

Dabei darf nicht vergessen werden, dass Ferdinand im Grunde keine andere Möglichkeit

69 Brook-Shepherd, Karl I., S. 198.

70 Ebd., S. 201.

71 Manfried Rauchensteiner, Der Erste Weltkrieg und das Ende der Habsburgermonarchie, S. 1026

72 Ebd., S. 1025

73 Brook-Shepherd, Karl I., S. 202. 
als die der bedingungslosen Kapitulation blieb. Die bulgarischen Truppen waren kriegsmüde und wollten nicht mehr kämpfen. Als dann auch noch Zeichen für eine "demokratischen Revolution“ im Raum standen, sah sich der Monarch gezwungen, die Flucht zu ergreifen. ${ }^{74}$

Was bedeutete die Kapitulation Bulgariens nun aber für die militärisch-politische Situation der Mittelmächte? Österreich-Ungarn und das Deutsche Kaiserreich besaßen mit einem Schlag keine Landverbindung mehr zu ihrem wichtigsten Verbündeten, dem Osmanischen Reich. Die Balkanfront, die schon seit längerer Zeit einzubrechen drohte, stand nun offen. Der alliierte Vormarsch war nicht mehr abzuwenden und Ungarn unmittelbar bedroht. ${ }^{75}$

Damit wurde die ohnehin schon angespannte militärische Lage verschärft, denn seit August fand an der Westfront eine groß angelegte Offensive der Alliierten statt, die die deutschen Kräfte band. Ein immer noch angestrebter "Siegfrieden“ war nun endgültig unmöglich geworden. ${ }^{76}$

\section{Entstehung des Völkermanifests}

Die Entstehung des Völkermanifests ist äußerst komplex und schwer zu rekonstruieren. Das hängt einerseits damit zusammen, dass es bis zum endgültigen Papier mehrere Entwürfe gab, die immer wieder abgeändert wurden. Andererseits ist es durch das Mitwirken zahlreicher Einzelpersonen, die ihre jeweiligen Ideen einbringen wollten, schwierig, den Überblick zu bewahren. Hinzu kommt die problematische Quellenlage: Aktenbestände und Dokumente sind nicht lückenlos vorhanden. Man muss sich daher primär auf die Memoiren und Tagebücher der beteiligten Akteure stützen. In Kombination mit den verfügbaren Verfassungsdokumenten kann eine Rekonstruktion der Entstehungsgeschichte des Völkermanifests versucht werden. ${ }^{77}$ In der Forschung setzte sich damit vor allem Helmut Rumpler auseinander. ${ }^{78}$ Auch Peter Broucek versuchte, die Entstehung des Völkermanifests wiederzugeben. ${ }^{79}$

\section{Kaiser Karls Initiative}

In seiner Thronrede vor dem Reichsrat im Mai 1917 bekundete Kaiser Karl seinen Reformwillen und betonte die Notwendigkeit einer "Ausgestaltung der verfassungs- und verwaltungsrechtlichen Grundlagen des gesamten öffentlichen Lebens, sowohl im Staate, als in den einzelnen Königreichen und Ländern, insbesondere in Böhmen. “80 Er sah die Gewährleistung der „freien nationalen und kulturellen Entwicklung gleichberechtigter

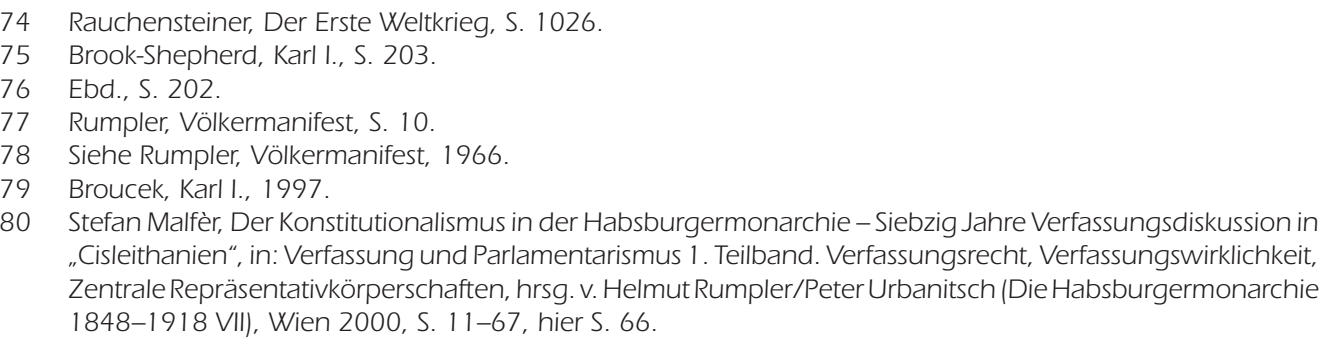


Völker" durch eine Zusammenarbeit zwischen der Krone und den Abgeordneten des Reichsrats vor. ${ }^{81}$ Das entsprach ganz der Auffassung Karls von seiner Regierung, denn er wollte konstitutionell regieren, nicht totalitär. Der Reichsrat hatte seit 1914 nicht mehr sistiert. Die Regierung regierte auf der Basis des Paragraphen 14 der cisleithanischen Verfassung von 1867, der besagte, dass der Kaiser in Krisenzeiten das Recht habe, mittels Verordnungen vorübergehend Gesetze zu erlassen. De facto konnte die Regierung Cisleithaniens ohne den Reichsrat Gesetze beschließen. Durch die kaiserliche Unterschrift erlangten diese dann ihre Rechtskraft. ${ }^{82}$ Karl war kein Freund des Paragraphen 14 und lehnte es vermutlich auch deshalb ab, den Eid auf die österreichische Verfassung zu leisten. Er war von der Notwendigkeit einer modifizierten, reformierten Verfassung überzeugt. ${ }^{83}$

Sowohl Gordon Brook-Shepherd als auch der Historiker Stefan Malfèr sind der Meinung, dass die Thronrede Karls hinter den Erwartungen zurückgeblieben sei. In jedem Fall aber wurde die Verfassungsdebatte durch die persönliche Initiative des Kaisers weiter angefacht und intensiviert. ${ }^{84}$ Geht es nach Peter Broucek, hatte Karl bereits seit 1914 bzw. 1916 die Idee zur Bildung eines Staatenbundes gehabt. Schon als junger Erzherzog hegte er föderative Gedanken und lehnte sowohl den Dualismus ${ }^{85}$ als auch den Trialismus ab. Karl war in die Reformpläne seiner Minister stark involviert, gab persönliche Anweisungen und ließ realistische Konzepte zur Verfassungsreform entwickeln. ${ }^{86}$ Der Kaiser hatte sich somit selbst maßgeblich am endgültigen Entwurf des Völkermanifests beteiligt.

\section{Föderalisierungsbestrebungen 1914-1918}

Eine Verfassungskrise in Cisleithanien lässt sich laut Stefan Malfèr spätestens ab 1897 diagnostizieren. Es gab mehrere Bestrebungen und Vorschläge, um mittels Reformen einen Ausweg zu finden. ${ }^{87}$ Schon im März 1914 wurde das Parlament aufgrund der ungelösten böhmischen Frage fristlos vertagt. Unter Ministerpräsident Karl Stürgkh (1859-1916) wurde die Neuordnung der Verfassung diskutiert und in Auftrag gegeben. Viel kam dabei allerdings nicht heraus, auch weil Stürgkh 1916 ermordet wurde. ${ }^{88}$

Im Dezember 1915 gründete der einflussreiche Großkaufmann Julius Meinl II. (18691944) die "Österreichische Politische Gesellschaft", deren Führung, neben Meinl selbst, dem Staatsrechtler Heinrich Lammasch (1853-1910) und dem Juristen Josef Redlich (1869-1936) - beide Abgeordnete zum Reichstag - oblag. Ziel dieser Vereinigung war

81 Maflèr, Konstitutionalismus, S. 66

82 Brook-Shepherd, Um Krone und Reich, S. 125.

83 Ebd., S. 125-26

84 Malfèr, Konstitutionalismus, S. 66

85 Zum Dualismus siehe Gerald Stourzh, Der Umfang der österreichischen Geschichte. Ausgewählte Studien 1990-2010 (Studien zu Politik und Verwaltung 99). Wien-KöIn-Weimar 2011, S. 105-124. In seiner Studie „Die dualistische Reichstruktur, Österreichbegriff und Österreichbewusstsein 1867-1918“ von 1994 beschreibt Stourzh den Dualismus und seine Auswirkungen auf den Österreichisch-Ungarischen Staat bis zu dessen Zerfall 1918.

86 Broucek, Karl I. (IV.), S. 236.

87 Malfèr, Konstitutionalismus, S. 66.

88 Rumpler, Karl I. von Österreich (1916-1918), in: Die Kaiser der Neuzeit 1519-1918. Heiliges Römisches Reich, Österreich, Deutschland, hrsg. v. Anton Schindling/Walter Ziegler, München 1990, S. 382-394, hier S. 386 
es, in Diskussionsrunden über politische Fragen zu debattieren und Lösungsansätze zu finden. Dabei stand man dem Krieg kritisch gegenüber und suchte realistische Wege zum Frieden. Die „Beratungsgruppe für den Wiederaufbau Österreichs”, die innerhalb dieser Gesellschaft gegründet wurde, sollte über die Reformierung von Verfassung und Verwaltung debattieren. Wichtige Akteure waren dabei Universitätsprofessor Maximilian Freiherr von Hussarek-Henlein (1865-1935), der Publizist Benno Karpeles (1868-1938), Ignaz Seipel (1876-1932) und Heinrich Lammasch. ${ }^{89}$

Als Kaiser Franz Josef am 21. November 1916 starb, folgte inm Karl auf den Thron. Er beauftragte den neuen Ministerpräsidenten Heinrich Clam-Martinic (1863-1932) mit der Wiedereinberufung des Reichstags. Clam-Martinic wollte bezüglich der Verfassungsreform sowohl Föderalisten als auch Zentralisten zufriedenstellen, was im Endeffekt nicht gelingen konnte. Am 30. Mai 1917 wurde der Reichstag wieder einberufen. Die Abgeordneten der jeweiligen nationalen Gruppen brachten nun ihre Vorschläge für die Umgestaltung Österreichs ein, die teilweise stark voneinander abwichen. Clam-Martinic wurde am 19. Juni 1917 entlassen. Ihm folgte zunächst Dr. Ernst Seidler (1862-1931) als provisorischer Regierungschef. Nachdem sich Heinrich Lammasch nicht überreden ließ, das Amt des Ministerpräsidenten anzunehmen, blieb die Regierung Seidler bestehen. Die "Österreichische Politische Gesellschaft" strebte die Schaffung eines Friedensministeriums an. Das Projekt scheiterte jedoch vonseiten der Regierung aus personellen Gründen und konnte nicht umgesetzt werden. Im Laufe des Jahres 1917 entwickelte der Chef der kaiserlichen Hofkanzlei - Arthur Graf von Polzer-Hoditz (1870-1945) - zwei Denkschriften, die einen Mittelweg zwischen der Gewährung nationaler Autonomie für die einzelnen Völker und eines dennoch notwendigen zentralistischen Grundgerüsts bilden sollten. Der Einfluss von Polzers Schriften auf die Verfassungsdebatte ist schwer einzuschätzen und blieb eher gering. ${ }^{90}$

Im Juli 1917 wurde im Innenministerium die Abteilung für Verfassungsreform gegründet und Johann Andreas von Eichhoff (1871-1963) $)^{91}$ unterstellt. ${ }^{92}$ Insgesamt muss man festhalten, dass die Regierung Seidler bis zu Seidlers Rücktritt im Juli 1918 über eine Selbstverwaltung der jeweiligen Siedlungsgebiete diskutierte, aber kaum Schritte setzte, um eine solche zu erreichen. Außerdem wurden die Deutschösterreicher bevorzugt behandelt - Seidler bekannte sich kurz vor seinem Rücktritt offiziell zum „deutschen Kurs". Sein Nachfolger wurde schließlich Maximilian von Hussarek-Henlein. ${ }^{93}$

\section{Das Ministerium Hussarek}

Die Regierung Hussarek wurde für die endgültige Umsetzung der föderalistischen Idee von den Historikern entweder "gefeiert oder verdammt", so Helmut Rumpler. ${ }^{94}$

89 Broucek, Karl I. (IV.), S. 176-177

90 Ebd., S. 188-191.

91 Er war ein ehemaliger Vertrauter Franz Ferdinands und hatte bereits für den 1914 ermordeten Thronfolger einen Verfassungsentwurf erstellt.

92 Broucek, Karl I. (IV.), S. 195

93 Ebd., S. 202-203.

94 Rumpler, Völkermanifest, S. 6. 
Nicht beachtet wurde dabei laut Rumpler, dass Hussarek einer Föderalisierung im Sinne des Völkermanifests ablehnend gegenüberstand. Unterschrieben habe Hussarek schlussendlich nicht aus eigenem Antrieb. ${ }^{95}$ In der Einschätzung Rumplers ist HussarekHenlein daher nicht als maßgebender Akteur hinter dem Völkermanifest zu sehen.

Von der Regierung Hussarek gingen dennoch maßgebliche Impulse für eine Verfassungsreform des Habsburgerreiches aus, die letztlich im Erlass des Manifests gipfelten. Hussarek war insgesamt vier Monate Ministerpräsident der österreichischen Reichshälfte. Laut Rumpler übernahm er bezüglich des Verfassungsproblems im Wesentlichen die Politik der Vorgängerregierungen Clam-Martinic und Seidler. ${ }^{96}$ Ein innenpolitischer Kurswechsel fand unter Hussarek nicht statt. Während aber bei seinen Vorgängern die deutsch-tschechischen Differenzen als Schwerpunkt bei der Lösung der Verfassungsfrage galten, erweiterte Hussarek den Reformgedanken um die südslawische Frage. ${ }^{97}$ In diesem Bereich konnte er neue Ansätze liefern. ${ }^{98}$

Nicht zuletzt die Initiative in der südslawischen Frage schuf inm den Ruf eines aufrechten Reformers. Laut Rumpler war es aber auch der nachträglich konstruierte Zusammenhang der Ansätze Hussareks mit dem Völkermanifest. Denn Hussareks Vorstellung von Föderalisierung war eine andere als jene der Idee der Bildung eines Staatenbundes. Er war ein Gegner des Dualismus, aber auch der Dezentralisierung und wollte keine „eigenständigen staatlichen Gemeinwesen“ aller Nationalitäten, wie sie im Manifest in Aussicht gestellt wurden. ${ }^{99}$ Der Föderalismus sollte daher nach Hussarek nur bei der Lösung des südslawischen Problems angewandt werden. Sein quadralistischer Vorschlag sah die Bildung von vier Reichsteilen vor - Österreich mit den „deutschen Alpenländern“ und dem Sudetenland, Ungarn, Kroatien samt "Nebenländern“ und Galizien, das ein autonomes ukrainisches Gebiet beinhalten sollte. Im Prinzip war dies eine Erweiterung des trialistischen Konzepts, ${ }^{100}$ das einen Ausbau des dualistischen Systems mit den österreichischen und ungarischen Reichsteilen um eine staatsrechtliche Vereinigung der südslawischen Länder vorsah. ${ }^{101}$

Hussarek konnte seine eigenen Pläne schlussendlich aber nicht in die Tat umsetzen und musste sich fügen.

Durch die Einbindung der „Österreichischen Politischen Gesellschaft" und Johann Andreas von Eichhoff samt der Abteilung für Verfassungsreform entstanden mehrere Entwürfe für ein Manifest. ${ }^{102}$ Die endgültige Fassung wurde schließlich am 16. Oktober 1918 publiziert

95 Rumpler, Völkermanifest, S. 7.

96 Unter Ernst von Seidler war das Verfassungsdepartement im Ministerratspräsidium gegründet worden. Hussarek übernahm diese Institution unverändert. Auch das Kabinett Seidlers übernahm er beinahe vollständig, siehe Rumpler, Völkermanifest, S. 11.

97 Siehe dazu Janko Pleterski, Die Südslawenfrage, in: Die letzten Jahre der Donaumonarchie. Der erste Vielvölkerstaat im Europa des frühen 20. Jahrhunderts, hrsg. v. Mark Conrwall, 2. Auflage, o.0. 2006, S. 126-154.

98 Rumpler, Völkermanifest, S. 11

99 Ebd., S. 12-13.

100 Siehe dazu Janko Pleterski, Die Slowenen, in: Die Völker des Reiches, 2. Teilb., hrsg. v. Adam Wandruszka/ Peter Urbanitsch (Die Habsburgermonarchie 1848-1918 III), Wien 1980, S. 801-838, hier S. 833-831.

101 Rumpler, Völkermanifest, S. 14

102 Dazu genauer Rumpler, Völkermanifest. 
und einen Tag später in einer Extra-Ausgabe der Wiener Zeitung veröffentlicht. Sie war von Eichhoff und Hussarek redigiert und im Kronrat am Nachmittag des 15. Oktobers besprochen worden. Zuletzt wurde dieser Entwurfvon Außenminister Burian kontrolliert. ${ }^{103}$

\section{Reaktionen auf den Erlass des Völkermanifests}

\section{Medien - Reaktionen der deutschsprachigen Presse Cisleithaniens}

Im Laufe des 19. Jahrhunderts übernahmen die Medien eine immer wichtigere Vermittlerfunktion in einer sich zunehmend differenzierenden Gesellschaft. Die Kommunikation zwischen Politik, Wirtschaft, Kultur und der Gesellschaft wurde ebenso erweitert wie die Möglichkeit einzelner gesellschaftlicher Gruppen, ihre Interessen zu vertreten und zu verbreiten. Vor allem die Tageszeitungen sind gegen Ende des 19. und Anfang des 20. Jahrhunderts als Motor eines wachsenden und intensivierten öffentlichen Kommunikationsraums auszumachen. ${ }^{104}$ Ein modernes Zeitungswesen entwickelte sich in der Habsburgermonarchie später als in anderen Ländern Westeuropas. Die Analyse der Zeitungen als "Spiegel des gesamten politischen und geistigen Lebens“ (Hanna Domandl), besonders durch die Wechselwirkung zwischen Presse und Leserschaft, bietet die Chance, einen Einblick in die realpolitischen und gesellschaftlichen Vorgänge in Österreich-Ungarn im Herbst 1918 zu gewinnen. ${ }^{105}$

In dieser Arbeit werden explizit nur ausgewählte deutschsprachige Tageszeitungen behandelt, die primär in der österreichische Reichshälfte der Habsburgermonarchie erschienen sind. 1880 zählt man für diesen Raum 65 Tageszeitungen mit einer Gesamtauflage von ca. einer halben Million. Innerhalb von dreißig Jahren stieg die Anzahl der Tageszeitungen um 250\% auf 161 im Jahr 1910. ${ }^{106}$ Diese Zahlen ermöglichen es, eine Vorstellung des gesellschaftlichen Wandels zu gewinnen, den die Habsburgermonarchie in ihren letzten Jahren durchlief. ${ }^{107}$ Die wachsende Rolle der Presse als Intermediär zwischen Politik und Bevölkerung brachte insbesondere eine Ausweitung der Bedeutung der politischen Presse mit sich. ${ }^{108} \mathrm{Im}$ Folgenden werden die Reaktionen von fünf deutschsprachigen Tageszeitungen Cisleithaniens auf das Völkermanifest analysiert. Die Tageszeitungen vertraten eine jeweils andere politische Linie und richteten sich an unterschiedliche Zielgruppen.

103 Broucek, Karl I. (IV.), S. 210.

104 Bachleitner/Seidler, Medialisierung gesellschaftlicher Kommunikation, S. 235-236

105 Domandl, Kulturgeschichte, S. 462-463.

106 Für die Recherche dieser konkreten Zahlen wurden die Volkszählungen der Monarchie von 1880 und 1910 als Ausgang genommen, um für die Zeitungsentwicklung "soziodemographische Merkmale“ miteinzubeziehen, vgl. Bachleitner/Seidler, S. 236, Anmerkung Nr. 7.

107 Bachleitner/Seidler, Medialisierung gesellschaftlicher Kommunikation, S. 236-237.

108 Ebd., S. 241. 


\section{"Neue Freie Presse"109}

Die "Neue Freie Presse" entstand 1864 infolge einer Zeitungsrevolte unter Mitarbeitern der "Presse". ${ }^{110}$ Sie konnte sich relativ schnell als wichtige Tageszeitung etablieren und zeichnete sich vor allem durch Aktualität und einen hohen Informationsgrad aus. Neben der Berichterstattung über europäische Geschehnisse wurden auch außereuropäische Ereignisse thematisiert. ${ }^{111}$ In ihrer politischen Ausrichtung trat die "Neue Freie Presse" als bürgerlich-liberale Tageszeitung auf, die als besonders verfassungstreu galt. Des Weiteren war sie prinzipiell "deutschfreundlich" eingestellt, stand aber hinter dem Ausgleich mit Ungarn von 1867. Innenpolitisch wurde der Zentralismus befürwortet. ${ }^{112}$

Die Einstellung der "Neuen Freien Presse“ zum Völkermanifest kann durchwegs als ablehnend beschrieben werden. Es könne „[...] nur verstanden werden als Teil der Friedensarbeit des Kaisers Karl, [...] aus seiner beständigen Sorge, die Monarchie hinüberzuretten in eine bessere Zeit." Dem Kaiser wurde ein Wille zum Frieden und zur Erhaltung der Monarchie bescheinigt. Er wurde nicht kritisiert. Sein Konzept der Bildung eines Staatenbunds wurde allerdings bemängelt, es sei nicht detailliert genug: „[...] nirgends wird uns die Regierungsgewalt, welche die Teile wieder zu einem Ganzen vereinigen könnte, gezeigt." Des Weiteren wird die angespannte Situation zwischen den Völkern realistisch eingeschätzt: „Wir sind in dem bedenkliche Zustande, daß die Völker schon jetzt sich in die Selbständigkeit einspinnen, das Trennende lebhaft empfinden, [...] während die Macht, das Gemeinsame zu schätzen, verschwindet." Eine gewisse Skepsis bezüglich der Durchführbarkeit der im Manifest geäußerten Pläne war erkennbar. Auch zynische Bemerkungen blieben in diesem Zusammenhang nicht aus: „Ein Bundesstaat aus Völkern, die sich meistens gegenseitig nicht ausstehen können, in Sprache und Gesinnung sich unterscheiden und den inneren Frieden schon früher in der Absonderung gesucht haben, wird nicht leicht zu gründen sein. “113

Zuletzt wurde die Ablehnung des Manifests klar zum Ausdruck gebracht. Das Manifest sei nichts anderes als ein Kniefall vor den Alliierten: „Der Bundesstaat, die Vereinigten Staaten von Österreich, schon der Name ist eine Verbeugung vor Wilson. So haben wir ein Ministerium Wilson, genannt Hussarek." ${ }^{114}$

Der Zerfall der Monarchie schien in den Augen der "Neuen Freien Presse“ eigentlich besiegelt. Interessant ist, dass sich die Kritik hauptsächlich auf den Ministerpräsidenten Hussarek konzentrierte, während der Kaiser geschont wurde.

109 Neue Freie Presse, 18. Oktober 1918, [http://anno.onb.ac.at/cgi-content/anno?aid=nfp\&datum=1918101 8\&zoom=33], eingesehen 18.07.2014.

110 Ehrenpreis, Reichsweite Presse S. 1733-1734.

111 Ebd., S. 1738.

112 Ebd., S. 1740

113 Neue Freie Presse, 18. Oktober 1918, [http://anno.onb.ac.at/cgi-content/anno?aid=nfp\&datum=1918101 8\&zoom=33], eingesehen 18.07.2014. 


\section{"Arbeiter-Zeitung" und "Arbeiterwille"}

a) „Arbeiter-Zeitung“115

Die „Arbeiter-Zeitung“ wurde 1889 von Victor Adler (1852-1918) gegründet. Sie erschien ab dem 1. Jänner 1895 täglich und hatte sich zu diesem Zeitpunkt bereits als das zentrale Organ der Sozialdemokratischen Arbeiterpartei etabliert. ${ }^{116}$ Ein Hauptanliegen der Zeitung war die Durchsetzung des allgemeinen, gleichen und direkten Wahlrechts. ${ }^{17}$ Auch abseits des Wahlthemas mischte sie sich kräftig in den politischen Diskurs ein. Insbesondere die Regierungstätigkeit bürgerlich-liberaler Kreise wurde angeprangert, während die „Errungenschaften der Arbeiterklasse“ gelobt wurden. ${ }^{118}$ Es kam zu heftigen Auseinandersetzungen mit Zeitungen, die eine andere politische Einstellung vertraten. Vor allem die liberale "Neue Freie Presse”, die konservative Zeitung "Vaterland“ sowie die christlich-sozial ausgerichtete "Reichspost“ waren beliebte Angriffsziele. ${ }^{119}$

"Gut gemeint - das kann man vielleicht von dem Manifest sagen [...]", war die zentrale Charakterisierung des Manifests seitens der "Arbeiter-Zeitung”. Es hätte "geschichtliche Bedeutung" erlangt, wenn es "aus freiem Entschluß”, aus der Erkenntnis, dass eine Neugestaltung notwendig sei, und rechtzeitig, also sprich früher, postuliert worden wäre. Auch diese Zeitung betonte, dass die Maßnahmen zum Umbau Österreichs zu spät kämen. Wie die "Neue Freie Presse“ bemängelte die "Arbeiter-Zeitung”, dass im Manifest kaum Konkretes zur Bildung eines Staatenbunds angekündigt wird: „Im Übrigen ist zu beachten, daß dieses Manifest nicht viel mehr ist als die Verkündigung eines Konzepts; praktisch ist darin nur gesagt, dass die Regierung beauftragt sei, zum Neuaufbau Österreichs ohne Verzug alle Arbeiten vorzubereiten."120

Die „Arbeiter-Zeitung" stand dem Manifest nicht grundsätzlich ablehnend gegenüber. Es wurde eher eine resignierende, enttäuschte Haltung zum Ausdruck gebracht.

b) „Arbeiterwille“121

"Der Wortlaut des Manifests bestätigt, daß auch jetzt wieder die alte österreichische Devise gilt: Zu spät und halb.“" In der Zeitung „Arbeiterwille“, der sozialdemokratischen Parteizeitung der Steiermark, wurde Klartext gesprochen. Im Vordergrund standen der zu späte Zeitpunkt des Manifest-Erlasses und dessen unfertiger, konzepthafter Charakter. So wurde kritisiert, dass die Manifest-Pläne nicht für alle Völker Cisleithaniens gelten sollten, wie etwa für die Polen: „Die Erhaltung der Polen ist offenbar schon als hoffnungslos aufgegeben, da sie sich bereits auf Grund der Punkte Wilsons als Bürger des neuen Staates

115 Arbeiter Zeitung, 18. Oktober 1918, [http://anno.onb.ac.at/cgi-content/anno?aid=aze\&datum=19181018 \&seite= 1 \&zoom = 33]; eingesehen 19.07.2014.

116 Ehrenpreis, Reichsweite Presse, S. 1784

117 Ebd., S. 1785.

118 Ebd., S. 1787

119 Ebd., S. 1786

120 Arbeiter Zeitung, 18. Oktober 1918, [http://anno.onb.ac.at/cgi-content/anno?aid=aze\&datum=19181018 \&seite=1 \&zoom =33]; eingesehen 19.7.2014.

121 Ebd. 
Polen betrachten.“ Auch die Nichterwähnung der Italiener stieß auf Unverständnis: „Von den Italienern ist überhaupt nicht die Rede [... $]^{\prime \prime}{ }^{122}$

Summa summarum brachte die Zeitung „Arbeiterwille” eine ernüchternde Haltung zum Ausdruck: „Kurz, es scheint, als ob zwar wieder ein Schritt weiter in der Erkenntnis der Unhaltbarkeit des jetzigen Staatengebildes gemacht worden wäre, aber als ob dieser Schritt wieder hinter den Ereignissen zurückbleibt, zu spät und zu kurz ausgefallen ist."123

\section{"Reichspost"124}

Die „Reichspost" erschien ab 1894. Sie wurde gegründet, um die wenigen vorhandenen katholischen Tageszeitungen der Monarchie zu ergänzen und die christlich-soziale Bewegung zeitgemäß und angemessen zu vertreten. Sie stand in einem Nahverhältnis zur Christlich-Sozialen Partei, war aber nicht offizielles Parteiorgan. Jedoch trat das Blatt als politisches Sprachrohr der Parteimitglieder auf und konzentrierte sich auf die katholische Leserschaft. Neben der Treue zur Dynastie der Habsburger und einem zentralistischen Standpunkt verfolgte diese Zeitung die Forcierung einer Wahlrechts- und Sozialreform, die vor allem den Bauern und Landarbeitern, aber auch dem Arbeiterstand, zugutekommen sollte. Die "Reichspost" fungierte zudem als Organ gegen die sozialdemokratische und liberale Presse. Auch antisemitische Kampagnen, insbesondere bezogen auf wirtschaftliche Fragen, blieben nicht aus. ${ }^{125}$ Des Weiteren wurde grundsätzlich ein antimagyarischer und - besonders während der Julikrise 1914 - ein antiserbischer Kurs gefahren. Die "Reichspost” war „nicht zufällig [...] die erste Adresse für Leserzuschriften, die Vergeltung für den Thronfolgermord forderten."126

Am 18. Oktober 1918, einen Tag nach der Veröffentlichung des Völkermanifests, erschien zunächst das Morgenblatt der "Reichspost". Das Manifest sei "ein Aufruf des Trägers der Krone an seine Völker, zu dem Neubau des Staates zusammenzuwirken“. Der Kaiser würde sich auf den "Willen seiner Völker" berufen, die "nach dem Bundesstaate verlangen". Dass dies den tatsächlichen Gegebenheiten nicht entsprach, muss erwähnt werden. Das Manifest als "Wille des Volkes" darzustellen, lag fern jeder Realität. Im weiteren Text wurde Bezug auf eine mögliche Verfassung für einen neu gegründeten Bundestaat genommen. Sie sollte "tief aus dem Volke herauswachsen“. Die alte Verfassung von 1867 wurde in mehreren Punkten kritisiert. Sie sei auch letztlich der Grund für die zunehmend schwächer werdende Position der Deutschösterreicher im Vielvölkerreich und für den Aufstieg der tschechischen Nationalisten. In dem Sinn sei sie also verfehlt gewesen und in den langen Jahren ihres Bestands nie ganz akzeptiert worden. Sie habe nie wirklich gegriffen: „Es hängt nicht unser Herzblut an der ,Siebenundsechziger-Gesetzgebung', die einer anderen

122 Arbeiterwille, 18. Oktober 1918, [http://anno.onb.ac.at/cgi-content/anno?aid=awi\&datum=19181018\&z oom=33], eingesehen 19.07.2014.

123 Ebd.

124 Reichspost, 18. Oktober 1918, [http://anno.onb.ac.at/cgi-content/anno?aid=rpt\&datum=19181018\&zoo $\mathrm{m}=33$ ], eingesehen 19.07.2014.

125 Ehrenpreis, Reichsweite Presse, S. 1790

126 Ebd. 
politischen Geisteswelt entsprossen ist. Es war dem Einsichtigen schon lange klar, daß sie nicht mehr haltbar sei. “127

Den Plänen im Manifest stand die „Reichspost“ jedoch positiv gegenüber: „Der ,Staatenbund' ist das Programm der Zukunft". Der Kaiser wurde wohlwollend erwähnt und für seinen Einsatz für Frieden und den Fortbestand der Monarchie geadelt: „So wie alles in den bisherigen Regierungshandlungen Kaiser Karls I. edelstes Wollen ist, [...] so umströmt auch diese menschlich warme kaiserliche Kundgebung ein Geist, der Zuversicht und Vertrauen erweckt." ${ }^{128}$

In der Nachmittagsausgabe wurde Stellung zur Aufnahme und den Reaktionen gegenüber dem Manifest in der Bevölkerung genommen: „Man hat in fünfzig Kriegsmonaten das Überraschtsein verlernt". Demnach sei die Begeisterung für das Manifest gering. Der Krieg habe die Bevölkerung abgestumpft, sie sei nicht mehr aufnahmefähig für derartige politische Ankündigungen.

Die "Reichspost” stand dem Manifest und den Plänen zum Umbau Österreichs in einen Bundesstat - im Vergleich zu den anderen Blättern - äußerst positiv gegenüber und argumentierte auch ausführlich, warum die Situation Österreichs in Zukunft nur besser werden könne. Die alte Verfassung von 1867 war laut der "Reichspost" ungeeignet, wurde nie wirklich von der Bevölkerung angenommen, und war sogar Mitschuld an der Entwicklung des Zerfalls. Sie sei eine reine „Buchverfassung“. Der Kaiser wurde von der „Reichspost" für seinen Entschluss, den Völkern die Selbstbestimmung über ihre Zukunft zu gewähren, in den Himmel gelobt. Hier verband sich die Pro-Manifest-Haltung dieser Zeitung mit einer kaiserfreundlichen Grundeinstellung, nach dem Motto: „Der Kaiser wird schon wissen, was das Beste für sein Volk (oder seine Völker) ist."

\section{"Deutsches Volkshlatt"129}

Das „Deutsche Volksblatt“ galt als die bedeutendste deutschnationale und antisemitische Tageszeitung Österreich-Ungarns. Sie erschien von 1889 bis 1922. Unter den deutschnationalen Blättern vertrat sie eine gemäßigte Linie und nahm eine Haltung zwischen der "Ostdeutschen Rundschau“ - gegründet vom selbsternannten „Führer der Deutschradikalen" Karl Hermann Wolf - und der christlich-sozialen "Reichspost" ein. ${ }^{130}$ Im Ersten Weltkrieg trat diese Zeitung als großer Befürworter des Bündnisses ÖsterreichUngarns mit dem Deutschen Kaiserreich auf.

\section{Morgen-Ausgabe}

Das Manifest war, laut dem "Deutschen Volksblatt”, "unter starkem Druck der gesamteuropäischen Entwicklung" entstanden, worin aber kein Nachteil, sondern ein Vorteil

127 Reichspost, 18. Oktober 1918, [http://anno.onb.ac.at/cgi-content/anno?aid=rpt\&datum=19181018\&zoo $\mathrm{m}=33]$, eingesehen 19.07.2014.

128 Ebd

129 Deutsches Volksblatt, 18. Oktober 1918, [http://anno.onb.ac.at/cgi-content/anno?aid=dvb\&datum=1918 1018\&zoom=33], eingesehen 19.07.2014.

130 Domandl, Kulturgeschichte, S. 469-470. 
bestehe. „Es ist selbstverständlich, daß [...] das alte Verwaltungsgerüst bestehen bleiben muss", zumindest bis die Einzelstaaten entstanden seien. Hier wurde der Übergang vom „Alten zum Neuen" beschworen. Es wurde betont, dass für den reibungslosen Umbau Österreichs in einen Bundesstaat in der Übergangszeit die Aufrechterhaltung der gewohnten politischen Strukturen vonnöten sei. Im Manifest sei dies durchaus ebenso formuliert. ${ }^{131}$ Wie der Übergang im Detail erfolgen sollte, wurde darin allerdings sehr ungenau bzw. gar nicht dargestellt.

„Auf jeden Fall hat das kaiserliche Manifest die Bahn für eine friedliche Auseinandersetzung frei gemacht, [...] das ist ein Weg, der zu einem ehrenvollen Frieden führen kann." Der Begriff eines "ehrenvollen Friedens", der im Manifest verwendet wurde, musste laut dem „Deutschen Volksblatt” doppelt unterstrichen werden. Denn im weiteren Text wird auf die „Deschämenden Erscheinungen“ im ungarischen Abgeordnetenhaus hingewiesen, wo offenbar für einen "Sonderfrieden“ Ungarns Stimmung gemacht worden war. Die Ungarn hofften demnach durch einen „Bulgarismus von Wilson vielleicht bessere Friedensbedingungen zu erbetteln. “132

Die Ungarn wurden in diesem Artikel des Verrats angeklagt: „[...] Frieden durch Verrat zu erkaufen, ist ehrlos. [...] Graf Tisza in eigener Person trat den Buß- und Bettelgang zur Entente an." Am Schluss wurde davon abgeraten, dass ein neu gegründeter, eigenständiger Staat der „Deutschösterreicher" weiterhin engere Beziehungen zu den Ungarn pflege. Argumentiert wird auch damit, dass es die Ungarn gewesen seien, die den Dualismus „eingesargt" hätten, so die Formulierung. ${ }^{133}$

Mittags-Ausgabe

Titel: „Der Eindruck des Manifestes”

In der Mittagsausgabe schrieb das „Deutsche Volksblatt”, dass „ [...] die Hoffnungen, die man auf das Gelingen des Planes eines Neuaufbaus der Monarchie setzt, sehr geringe sind“. Es wurde nicht an den Erfolg des Manifests geglaubt. Auch das Zuspätkommen wurde angesprochen: „Vielfach wird der Meinung Ausdruck gegeben, daß der Appell an die Völker zu spät erfolgte. “134

Dennoch wurde darauf hingewiesen, dass der Prozess der Konstituierung von eigenen Staaten bereits stattfände. Es sei „zu begrüßen, daß die Deutschen Parteien“ dem "Grundsatze des nationalen Selbstbestimmungsrechtes uneingeschränkte Geltung [...] verschaffen". Dem Manifest wurde, obwohl keiner an dessen Erfolg glaubte, trotzdem etwas Positives abgewonnen: Die bevorstehende Gründung eines eigenen Staates der "Deutschösterreicher". Es wurde sogar recht optimistisch in die Zukunft geblickt: „Wenn die Deutschen Österreichs [...] sofort die richtigen Folgerungen ziehen, [...] kann ihnen um ihr Schicksal nicht bange sein.“ Gleichzeitig nahm man die „politische Führung der

131 Es ist hier von den „bestehenden Einrichtungen“ die Rede, die „zur Wahrung der allgemeinen Interessen unverändert aufrecht" bleiben sollen, siehe Text im Völkermanifest.

132 Deutsches Volksblatt, 18. Oktober 1918, [http://anno.onb.ac.at/cgi-content/anno?aid=dvb\&datum=1918 1018\&zoom=33], eingesehen 19.07.2014. 
Deutschen“ in die Pflicht, sich voll und ganz auf die Konstituierung eines neuen Staates zu konzentrieren. Die geforderten Politiker sollen „auf der vollen Höhe ihrer Aufgaben” stehen, "die zu den schwierigsten und verantwortungsvollsten gehören, vor die ein Volk jemals gestellt war". ${ }^{135}$

Im „Deutschen Volksblatt“ wurde dem Völkermanifest nur eine geringe Aussicht auf Erfolg attestiert. Man nahm eine pragmatische Haltung ein und akzeptierte die neu entstandene Lage. Gleichzeitig wurden neue Chancen für die „Deutschösterreicher“ in der Konstituierung eines eigenen Staates gesehen. Darauf solle man sich nun konzentrieren. Dieser Forderung wurde durch eine übertriebene Betonung der Bedeutung eines solchen Schrittes - gemeint ist die Bildung eines Staates der Deutschösterreicher - Nachdruck verliehen. Im „Deutschen Volksblatt“ mussten die Ungarn als Sündenböcke herhalten und wurden als Verräter bezeichnet.

\section{Politik und Bevölkerung}

Der folgende Bericht der Wiener Polizeidirektion vom 18. Oktober 1918 gibt Einblicke in die Reaktionen auf das Manifest in der Bevölkerung sowie den politischen Gruppierungen:

„Das in der heutigen Tagespresse veröffentlichte Manifest Seiner k. u. k. Apostolischen Majestät an die österreichischen Völker [...] hat in den breiten Massen der Bevölkerung, die dieser Allerhöchsten Kundgebung zukommende Bedeutung nicht gefunden. Dies hat seinen Grund vor allem darin, daß die unteren Schichten nur den Ernährungsverhältnissen Interesse entgegenbringen, politischen Vorgängen jedoch ziemlich abgestumpft gegenüber stehen.

In den deutschnationalen Kreisen macht sich nun angesichts dieser Haltung der nichtdeutschen Völker [...] eine lebhafte Propaganda dafür bemerkbar, daß sich nunmehr auch die Deutschen auf sich selbst besinnen und den Anschluß an das deutsche [sic!] Reich suchen sollen. Bemerkenswert erscheint, daß sich auch die sozialdemokratische Parteipresse in ganz ähnlichen Gedankengängen bewegt und [...] dem als berechtigt anerkannten Streben der Deutsch-Österreicher nach dem Anschlusse an das Deutsche Reich durch den Hinweis darauf Nachdruck zu verleihen bestrebt ist, daß ein solcher Anschluß nicht bloß aus völkischen Gründen, sondern [...] auch aus wirtschaftlichen Gründen erstrebenswert sei.

Im christlichsozialen Lager herrscht allgemein die Anschauung, daß eine gedeihliche Neugestaltung Österreichs [...] nur dann zu gegenwärtigen sei, wenn auch die Länder der ungarischen Krone sich einer Umgestaltung nach den gleichen Grundsätzen unterzögen. Auf diese Weise könnte das alte Ideal der christlichsozialen Partei, die Schaffung eines Groß-Österreich verwirklicht werden und die Monarchie trotz der Wahrung des Selbstbestimmungsrechtes der Völker nach außen hin ihre Machtstellung erhalten [...]. 
In den breiten Schichten der Wiener Bevölkerung wird, soweit das Manifest überhaupt diskutiert wird, die Bedeutung des Allerhöchsten Manifestes, vornehmlich in der Richtung erörtert, ob dasselbe zur baldigen Herbeiführung des Friedens Österreichs mit der Entente beitrage und ob und in welcher Weise die beabsichtigte Umgestaltung Österreichs die Ernährungsverhältnisse beeinflussen werde. In letzter Hinsicht wird besorgt, daß Deutsch-Österreich [...] eigentlich dem Verhungern preisgegeben werde, so daß auch aus diesem Grunde der Anschluß Deutsch-Österreichs an Deutschland zur Notwendigkeit werden könnte." ${ }^{136}$

Grundsätzlich lässt sich aus diesem Bericht die allgemein vorherrschende Haltung herauslesen: Das Manifest kam viel zu spät, um noch Einfluss auf die Ereignisse zu nehmen. Die gewünschte Wirkung des Aufrufs Karls an „seine Völker“ blieb deswegen aus. Hinsichtlich der Reaktionen der einzelnen politischen Lager ist interessant, dass sowohl deutschnationale als auch sozialdemokratische Kreise den Anschluss an Deutschland befürworteten. Die Christlich-Sozialen wünschten sich offenbar den Einbezug der ungarischen Reichshälfte in die Umgestaltung Österreichs. Die Stimmung, zumindest in der Wiener Bevölkerung, war nicht von Begeisterung für das Manifest geprägt. Die Menschen machten sich kaum Gedanken über den politisch-administrativen Neuaufbau Österreichs, sondern sorgten sich mehr um die Versorgung mit Nahrungsmitteln. Diesbezüglich gab es offenbar auch Bestrebungen in Richtung eines Anschlusses an Deutschland. Das Manifest wurde eher dahingehend diskutiert, welche Auswirkungen es auf einen möglichen Frieden haben könnte.

Ein wichtiges Ziel, das beim Erlass des Völkermanifests verfolgt wurde, war es, den USamerikanischen Präsidenten vom Reformwillen des Vielvölkerreiches zu überzeugen und doch noch zu Friedensverhandlungen zu bewegen. Am 20. Oktober 1918 kam die Antwort aus Washington:

„Der Präsident hält es für seine Pflicht, der österreichisch-ungarischen Regierung mitzuteilen, daß er sich mit dem vorliegenden Vorschlag dieser Regierung nicht befassen kann [...]. Unter den 14 Bedingungen, die der Präsident damals formuliert hatte, lautete eine: ,Den Völkern Österreich-Ungarns, deren Platz unter den Nationen wir geschützt und gesichert zu sehen wünschen, soll die freieste Möglichkeit zur autonomen Entwicklung gewährt werden ...' Seit dieser Satz geschrieben und vor dem Kongreß der Vereinigten Staaten ausgesprochen wurde, hat die Regierung der Vereinigten Staaten anerkannt, daß zwischen den Tschechoslowaken und dem Deutschen sowie österreichisch-ungarischen Reich der Kriegszustand besteht und daß der tschechoslowakische Nationalrat eine de facto kriegführende Regierung ist [...]. Sie hat auch in vollstem Umfang die Gerechtigkeit der nationalen Ansprüche der Jugoslawen auf Freiheit anerkannt. Der Präsident ist daher nicht mehr in der Lage, die bloße Autonomie dieser Völker als eine Grundlage für den Frieden anzuerkennen, sondern ist gezwungen, 
darauf zu bestehen, daß sie [die Völker] und nicht er [der Kaiser] Richter darüber sein sollen, welche Aktion auf Seiten der österreichisch-ungarischen Regierung die Aspirationen und die Auffassung der Völker von ihren Rechten und von ihrer Bestimmung als Mitglieder der Familie der Nationen befriedigen wird [... $]^{\text {“137 }}$.

Damit war klar, dass Wilson nicht mehr umzustimmen war. Brook-Shepherd bezeichnete die Antwort Wilsons auf das Manifest als „völlig unlogisch“. ${ }^{138}$ Kaiser Karl habe seinen Völkern nicht nur Autonomie gewährt, sondern Wilsons eigenes Prinzip der Selbstbestimmung als Grundlage für die zukünftige Entwicklung der Habsburgermonarchie genommen. Es sei demnach Wilson selbst gewesen, der sein eigenes Prinzip verleugnete und „verwirrt von den Emigrantenführern" gehandelt habe. ${ }^{139}$

Diese Sicht der Dinge scheint doch überspitzt zu sein. Allein durch die Anerkennung der Tschechoslowakei als offizielle kriegführende Macht auf der Seite der Allierten konnte Wilsons Antwort gar nicht anders lauten. Wie es dazu kam, wurde bereits erläutert. Zentral ist dabei die Tatsache, dass durch die gezwungene Hinwendung Karls zu den deutschen Verbündeten nach der "Sixtus-Affäre“ die Position der Emigrantenführer extrem aufgewertet wurde und sie als gleichrangige Partner dastanden. Die Sprengung der deutsch-österreichischen Allianz war endgültig gescheitert und somit auch kein Separatfrieden mit Österreich-Ungarn in Aussicht. Die Hinwendung Wilsons zu den Emigrantenführern war die logische Folge. Des Weiteren hatte Wilson in seiner Antwort auf das Manifest auch nüchtern erklärt, warum er es ablehnte: Seit der Verkündung seines 14-Punkte-Programms waren "gewisse Ereignisse von größter Bedeutung“140 eingetreten, die die Haltung der USA gegenüber Österreich-Ungarn geändert hatten. Von einer Verleugnung seines eigenen Prinzips der Selbstbestimmung kann daher eigentlich nicht gesprochen werden. Beim Erlass des Manifests wurde anscheinend davon ausgegangen, dass sich die Haltung der USA seit der Verkündung des 14-Punkte-Programms im Januar im Wesentlichen nicht geändert hatte. Damals musste man in den Vereinigten Staaten noch davon ausgehen, dass die "alte Ordnung” Europas nach dem Frieden bestehen bleiben könnte. Zwischenzeitlich hatten sich aber entscheidende Begebenheiten ereignet, wie eben die Anerkennung eines unabhängigen tschechoslowakischen Staates, die die Haltung der USA änderten. Im Oktober 1918 herrschte die Meinung vor, dass Europa auch „ohne seine zentralen Mächte“ weiterexistieren könne. ${ }^{141}$ Das Manifest kam daher auch in diesem Zusammenhang viel zu spät und hatte in außenpolitischer Hinsicht von vornherein kaum Aussicht auf Erfolg.

\section{Ablehnung des Manifests und endgültiger Zusammenbruch der Monarchie}

Von den nationalen Lagern Cisleithaniens wurde das Manifest abgelehnt. Ministerpräsident Hussarek lud die Vertreter der Nationen am 16. Oktober 1918 - einen Tag darauf sollte

137 Zit. n. Brook-Shepherd, Karl I., S. 213-214.

138 Brook-Shepherd, Karl I., S. 214.

139 Ebd.

140 Ebd., S. 213.

141 Ebd., S. 214. 
das Manifest veröffentlicht werden - zu Verhandlungen. Die Obmänner der Parteien des Abgeordnetenhauses wurden von den zentralen Punkten der Umwandlung Österreichs in einen Bundesstaat unterrichtet. Stellvertretend für die jeweilige nationale Gruppe sollten Nationalräte oder Nationalversammlungen gebildet werden, die einerseits die Errichtung neuer nationaler Staaten vorbereiten, andererseits den Zusammenhalt zwischen diesen Staaten garantieren sollten. Vorgesehen war die Bildung eines deutschösterreichischen, ${ }^{142}$ eines tschechischen, eines südslawischen und eines ukrainischen Staates. Der Prozess der Neugestaltung Österreichs sollte grundsätzlich im Parlament stattfinden. ${ }^{143}$ Dort würde die Regierung nach der Vorarbeit der einzelnen Nationalversammlungen Gesetze zur Umwandlung in einen Bundesstaat einbringen. ${ }^{144}$

Die Tschechen hatten an den Besprechungen mit Hussarek vom 16. Oktober gar nicht teilgenommen. In einem Schreiben entschuldigte sich der Verband der tschechischen Parteien für das Nichterscheinen. Die Gründe für die Ablehnung „einer solchen Lösung des tschechoslowakischen Staat[es]" seien dem Ministerpräsidenten bekannt. ${ }^{145}$ Die explizite Formulierung „tschechoslowakischer Staat“ liefert bereits den Grund für die Ablehnung der Tschechen. Denn die slowakische Bevölkerung befand sich fast ausschließlich auf dem Gebiet der ungarischen Reichshälfte. Die Integrität Ungarns sollte in den Umbauplänen des Manifests aber gewahrt bleiben. Die Bildung eines Staates bestehend aus Tschechen und Slowaken war nicht vorgesehen. ${ }^{146}$

Die Südslawen erschienen zwar zu den Besprechungen, nahmen aber kurz darauf Gespräche mit den tschechischen Abgeordneten auf. Es wurde ein gemeinsames Vorgehen mit den Tschechen vereinbart, was einer Absage der Südslawen an Hussarek gleichkam. Auch die ukrainische Abordnung brachte ihre Unzufriedenheit mit den Plänen der Umwandlung Österreichs zum Ausdruck. Die polnischen Abgeordneten nahmen an der Sitzung mit Hussarek ebenfalls nicht teil, da sie sich in Warschau befanden. Im Manifest wurde innen indirekt die Wahl gelassen, ob sie sich einem zukünftigen, neu errichteten polnischen Staat anschließen oder bei Österreich bleiben würden. Als auch von den deutschen Parteien eine offizielle Ablehnung der Manifest-Pläne erfolgte, war klar, dass die Neuordnung Österreichs nicht nach den im Völkermanifest niedergeschriebenen Leitlinien erfolgen konnte. ${ }^{147}$

Die Auflösung des Vielvölkerreichs war nicht mehr aufzuhalten. Am 18. Oktober kündigte Ungarn den Ausgleich von 1867 und damit die Realunion auf. Am 28. Oktober 1918 wurde die Tschechoslowakische Republik ausgerufen. Am 29. Oktober beschlossen die Kroaten den Zusammenschluss der südslawischen Gebiete und die Vereinigung mit Serbien. Am

142 Bei der Bildung des deutschösterreichischen Staates wurde der Anschluss Deutsch-Böhmes beabsichtigt.

143 Im Parlament bestanden bereits nationale Abgeordnetenverbände der Tschechen, der Südslawen (Südslawenklub), der Polen und der ukrainischen Abgeordneten. Auch die deutschen Abgeordneten wollten sich zu einem Klub zusammenschließen.

144 Kleinwaechter, Von Schönbrunn bis St. Germain, S. 69

145 Ebd., S. 70

146 Ebd. Der Tschechische Staat sollte nur aus dem nichtdeutschen Teil Böhmens, aus Mähren und Schlesien bestehen.

147 Kleinwaechter, Von Schönbrunn bis St. Germain, S. 71 
30. Oktober wurde die von Karl Renner ausgearbeitete provisorische Verfassung von der Nationalversammlung Deutschösterreichs angenommen. ${ }^{148}$ Am folgenden Tag wurde die erste deutschösterreichische Regierung unter Karl Renner (1870-1950) ins Amt berufen. Heinrich Lammasch, der Hussarek als Ministerpräsident nachgefolgt war, übergab die Regierungsgewalt und trat am 11. November 1918 zurück, nachdem Kaiser Karl die Verzichtserklärung unterschrieben hatte. ${ }^{149}$ Am 12. Oktober 1918 wurde die Republik Deutschösterreich ausgerufen. Am 16. November 1918 kam es schließlich zur Ausrufung der Republik Ungarn, ungeachtet dessen, dass ein großer Teil des Königreichs Ungarn von tschechischen, rumänischen und serbischen Heeresverbänden besetzt worden war. ${ }^{150}$

Ernst Hanisch bezeichnete den Zerfall der Donaumonarchie als "Revolution". Das Manifest habe zunächst als eine "Revolution von oben" dienen sollen, um den Alliierten die Bereitschaft zu Reformen zu demonstrieren. Dieses Ziel konnte nicht erreicht werden. Laut Hanisch gab das Manifest schlussendlich den letzten Anstoß zum Zerfall der Monarchie. ${ }^{151}$ Nicht minder dazu beigetragen hat der Krieg, der den Völkerkonflikt zusätzlich anheizte und die Durchführung von Reformen behinderte. Am 3. November 1918 wurde der Waffenstillstand unterzeichnet, 24 Stunden danach trat er in Kraft. Das Vielvölkerreich der Habsburger war Geschichte. ${ }^{152}$

\section{Bewertung und Einschätzung des Völkermanifests}

„Der Friedensschluss konnte [...] kein Österreich mehr vorfinden, das sich hätte neu einrichten können", schrieb Friedrich Kleinwaechter in seiner Einschätzung des Völkermanifests. ${ }^{153}$ Er bezog sich dabei auf den „ehrenvollen Frieden“, der in der Einleitung des Manifests versprochen wird. De facto war ein Frieden, bei dem die Habsburgermonarchie in ihrer bisherigen Beschaffenheit bestehen bleiben konnte, zum Zeitpunkt des Manifest-Erlasses längst nicht mehr möglich: Ein unabhängiger Staat der Tschechoslowakinnen und Tschechoslowaken war von den Alliierten bereits anerkannt worden, sogar als offizielle kriegführende Macht. Auch ein polnischer Staat sollte mit dem Einbezug österreichischer Gebiete wiedererrichtet werden. Italien wurde Triest, das Küstenland und die Brennergrenze vertraglich garantiert, Rumänien sollte die Bukowina und Siebenbürgen erhalten. ${ }^{154}$

Aber auch aus innenpolitischer Sicht war die Umsetzung des Manifests nicht durchführbar. Im Manifest wird den „Ländern der Ungarischen Heiligen Krone“ die volle Integrität

148 Die Abgeordneten der deutschen Parteien im Reichsrat hatten sich schon am 21. Oktober 1918 zur konstituierenden Nationalversammlung Deutsch-Österreichs zusammengeschlossen.

149 Karl I. verzichtete damit auf die Regierungsgeschäfte, nicht aber auf seine Krone. Am 13. Oktober unterschrieb er in Eckertsau eine ähnliche Verzichtserklärung bezüglich Ungarn, siehe Broucek, Karl I. (IV.), S. 215.

150 Franz Theuer, Schicksalsjahre Österreichs 1815-1914. Die großen Revolutionen und Kriege Europas, Eisenstadt 1999, S. 589-590.

151 Ernst Hanisch, Der lange Schatten des Staates. Österreichische Gesellschaftsgeschiche im 20. Jahrhundert, hrsg. v. Herwig Wolfram (Österreichische Geschichte 1890 - 1990), Wien 2005, S. 263.

152 Rauchensteiner, Ende des Großen Krieges, S. 44.

153 Kleinwaechter, Von Schönbrunn bis St. Germain, S. 63

154 Ebd., S. 62 
zugesichert. Die staatliche Neugestaltung sollte sich daher auf die österreichische Reichshälfte beschränken. Es wurde nicht berücksichtigt, dass damit weitere ethnische Konflikte vorprogrammiert waren. Denn mögliche südslawische und rumänische Einheitsstaaten wären nur aus den in Cisleithanien ansässigen südslawischen und rumänischen Bevölkerungsteilen gebildet worden. Die slawische Bevölkerung Kroatiens und Slawoniens befand sich allerdings in Transleithanien. Auch in Ungarn selbst gab es zahlreiche südslawische Siedlungen. Nordungarn besaß einen hohen Anteil an slowakischer Bevölkerung. Des Weiteren wären die Rumäninnen und Rumänen Siebenbürgens als Teil des ungarischen Hoheitsgebietes ebenfalls nicht berücksichtigt worden. ${ }^{155}$

Durch den Nichteinbezug der ungarischen Hälfte gerieten die Pläne, die im Manifest veranschaulicht wurden, von vornherein zur Farce. Ohne ungarische Zustimmung war ein sinnvoller Umbau der Monarchie zum Bundesstaat nicht möglich. Eine solche wurde von den Ungarn aber verweigert, da sie wussten, dass die magyarische Vormachtstellung in Transleithanien, die seit dem Ausgleich von 1867 bestand, mit der Bildung autonomer Bundesstaaten der Völker zu Ende sein würde. Der Eid Kaiser Karls auf die ungarische Verfassung, den er bei der Krönung zum König von Ungarn geleistet hatte, beeinträchtigte seinen Handlungsspielraum in dieser Frage. Ihn zu brechen galt eigentlich als unmöglich und wurde vom Kaiser vermutlich auch gar nicht in Betracht gezogen. Hinzu kam noch die Drohung des ungarischen Ministerpräsidenten Wekerle, die Lebensmittelzufuhr nach Österreich zu stoppen. Nicht zuletzt deshalb beschränkte man sich letztendlich im Völkermanifest auf die österreichische Reichshälfte und garantierte die Integrität der ungarischen Länder. ${ }^{156}$

Den entscheidendsten Fehler des Manifests sah Helmut Rumpler darin, dass einer Lösung des böhmischen Problems ausgewichen wurde. ${ }^{157}$ Dadurch, dass in Böhmen sowohl eine deutschösterreichische als auch tschechische Bevölkerung ansässig war, wäre es nach den Anweisungen im Manifest zu einer Aufteilung dieses Gebiets gekommen. Im vergleichbaren Fall von Galizien wurde die Teilung des Gebiets in einen polnischen und einen ukrainischen Teil beschlossen. ${ }^{158}$ Die Tschechen bestanden jedoch vehement auf der Unteilbarkeit des Königreichs Böhmen. Nach dem Prinzip der nationalen Selbstbestimmung war dieses Problem daher nicht lösbar, ohne die Tschechen vor den Kopf zu stoßen. ${ }^{159}$ Rumpler vermutete, dass aufgrund dieser Problematik keine endgültige Lösung für das böhmische Gebiet gefunden worden sei und auch nicht gefunden werden wollte. Weder die Tschechen noch die Deutschösterreicher sollten kompromittiert

155 Kleinwaechter, Von Schönbrunn bis St. Germain, S. 63

156 Ebd., S. 64-66.

157 Siehe dazu Catherine Albrecht, Die Böhmische Frage, in: Die letzten Jahre der Donaumonarchie. Der erste Vielvölkerstaat im Europa des frühen 20. Jahrhunderts, hrsg. v. Mark Conrwall, o. O. 2006, S. 85-106.

158 Der ukrainische Teil wäre dabei als Bundesstaat bei Österreich geblieben, während der polnische Teil an einen neugeschaffenen polnischen Staat abgetreten worden wäre. Auch im Manifest-Text wurde klar dargelegt, dass der Neuaufbau Österreichs dem Polens nicht im Weg stehen sollte: „Der Vereinigung der polnischen Gebiete Österreichs mit dem unabhängigen polnischen Staate wird hiedurch in keiner Weise vorgegriffen."

159 Rumpler, Völkermanifest, S. 60. 
werden. Durch die Unbestimmtheit des Selbstbestimmungsrechts im Manifest - es wurde nur davon gesprochen, dass ,jeder Volksstamm auf seinem Siedlungsgebiete sein eigenes staatliches Gemeinwesen“160 bilden dürfe - wurden viele Probleme nicht konkret angegangen. Strittige Fragen - wie etwa der erläuterte böhmische Fall - blieben durch die neutralen Formulierungen im Manifest-Text offen. ${ }^{161}$

Rumpler bewertete das Völkermanifest als "Verzweiflungstat eines um die Zukunft seines Reiches besorgten Monarchen“162. Er sah es primär als "Friedensschritt der Monarchie“, und als solchen habe es auch Kaiser Karl verstanden wissen wollen. Deshalb sei dieses Dokument auch trotz der gravierenden Mängel in verfassungsrechtlicher Hinsicht und trotz seines unvollkommenen Charakters erlassen worden. Die außenpolitischen Interessen, ${ }^{163}$ die für das Manifest eine bedeutende Rolle gespielt hätten, sind laut Rumpler allzu häufig vergessen worden. In der Forschung habe man das Manifest meist als ein "Verfassungsdokument mit rein innerpolitischer Zielsetzung" bewertet. ${ }^{164}$ Des Weiteren sah Rumpler im Manifest auch den Beweis für die "tragische Ausweglosigkeit des österreichisch-ungarischen Nationalitätenstreits"165. Es sei auch deswegen gescheitert, weil das Prinzip der nationalen Selbstbestimmung nicht als geeignete Lösung des österreichischungarischen Verfassungsproblems verwendet werden konnte. Das Völkermanifest habe sich schlussendlich zu einem „unentwirrbaren, in sich unlogischen und daher realpolitisch unsinnigen Projekt" entwickelt, wurde aber dennoch in der Hoffnung auf eine Abwendung der bevorstehenden Auflösung des Reiches erlassen. Viel bedeutender als das Manifest selbst schätzte Rumpler die Reformpläne der Regierung Hussarek ein. Die Idee eines föderalistischen Umbaus der Verfassung im Sinne des Quadralismus hätte am ehesten die Chance auf Erfolg gehabt. Realpolitisch sei sie im Herbst 1918 jedoch nicht (mehr) durchführbar und somit nur von theoretischer Bedeutung. ${ }^{166}$

"Das Manifest war ein Schlag ins Wasser", schrieb Friedrich Kleinwaechter. ${ }^{167}$ Es habe seinen ursprünglichen Zweck, mit dem Umbau Österreichs einen Fortbestand des Vielvölkerstaats zu ermöglichen, klar verfehlt. Eines aber sei durch das Manifest ermöglicht worden: Die „unblutige Auflösung der Monarchie“168. Kleinwaechter war der Meinung, dass es ohne das Manifest zur Bildung von radikalen Vertretungsgruppen der Nationalitäten gekommen wäre, die ihre Forderungen mit aller Härte durchgesetzt hätten. Durch die Aufforderung an die ehemaligen Reichsratsabgeordneten zur Bildung von Nationalräten sei eine legale

160 Siehe Text im Völkermanifest.

161 Rumpler, Völkermanifest, S. 61.

162 Ebd., S. 63.

163 Rumpler dachte hier an die Absicht den Willen zum Frieden mittels des Manifests zu vermitteln. De facto kann dieser Wunsch nach Frieden bei gleichzeitigem Fortbestand der Monarchie im Oktober 1918 als realitätsfern bezeichnet werden. Die Auflösung Österreich-Ungarns war nicht mehr aufzuhalten, auch nicht bei sofortigem Friedenschluss. Die Alliierten hatten sich längst von dem Gedanken an einen möglichen Fortbestand des Vielvölkerreichs nach dem Frieden verabschiedet.

164 Rumpler, Völkermanifest, S. 63.

165 Ebd.

166 Ebd., S. 63

167 Kleinwaechter, Von Schönbrunn bis St. Germain, S. 72

168 Ebd., S. 75 
Grundlage für die Lösung der Auseinandersetzungen auf politischer Ebene geschaffen worden. Ein „Kampf aller gegen alle“ ist dadurch verhindert worden. ${ }^{169}$

In der Einleitung wurde die Hypothese formuliert, dass das Völkermanifest die Auflösung der Habsburgermonarchie nicht verhinderte oder stoppte, sondern sogar beschleunigte. Der Aufruf Kaiser Karls an "seine Völker“ zur Bildung von "Nationalen Räten“ habe auch die Legitimationsgrundlage zur Bildung von eigenständigen Staaten dargestellt. Die nationalen Gruppen hätten zwar den Ruf ihres Kaisers erhört, konstituierten aber von Habsburg gänzlich unabhängige Staaten. Die Idee eines Staatenbunds freier Völker habe sich nicht durchsetzen können. Insofern sei das Völkermanifest als Autorisierung zur Selbständigkeit verstanden worden und habe damit die Auflösung des Vielvölkerreichs gefördert.

Nach dem Studium der relevanten Literatur muss diese Hypothese allerdings relativiert werden. „Das Völkermanifest des Kaisers hat den Zerfall des Vielvölkerstaates nicht mehr verhindert, kaum beschleunigt, eher abgeschlossen", schrieb Rudolf Neck. ${ }^{170}$ Dass der Zerfall durch das Manifest nicht verhindert wurde, ist Fakt. Dass der Erlass des Manifests viel zu spät kam, hat sich ebenfalls herausgestellt. Ob nun aber dadurch die Auflösung beschleunigt wurde, ist schwer einzuschätzen. Das Manifest wurde am 16. Oktober 1918 erlassen und einen Tag darauf veröffentlicht. Bereits am 6. Oktober hatte sich in Zagreb der "Narodno Vijece" konstituiert, ein slowenisch-kroatisch-serbischer Nationalrat, dessen Ziel die Bildúng eines souveränen Staates war. Am 14. Oktober wurde die Konstituierung der Tschechoslowakischen Republik von der Tschechischen Exilregierung in Paris unter Edvard Beneš verkündet. Zur gleichen Zeit organisierte der tschechische Nationalausschuss "Národni Vybor" einen Generalstreik samt Lebensmittelblockade gegen die deutschösterreichischen Gebiete. Am 15. Oktober wurden seitens der polnischen Abgeordnetenversammlung in Krakau die Eigenständigkeit eines zukünftigen polnischen Staates und die Zugehörigkeit der polnischen Gebiete in Österreich zu diesem bekräftigt. ${ }^{171}$

Das heißt also, dass die einzelnen Völker bereits vor dem Manifest Maßnahmen setzten, die in Richtung Eigenstaatlichkeit gingen. Das Manifest stieß deshalb nicht mehr auf die erhoffte Zustimmung, da sich die nationalen Gruppen bereits eigene Konzepte zur Zukunft ihrer Gebiete zurechtgelegt hatten. Deshalb wurde die Auflösung durch den Erlass des Manifests auch kaum beschleunigt - sie war schon beschlossene Sache. Was allerdings durchaus als richtig gelten kann, ist die Annahme, dass das Manifest die Auflösung legitimierte. Selbst wenn die Völker einer solchen Legitimation von oben nicht unbedingt bedurften, so stellte das Manifest - aus rechtlicher Sicht - die Bevollmächtigung zur legalen Bildung von eigenen Nationalräten und im Endeffekt zu eigenen Nationalstaaten dar.

169 Kleinwaechter, Von Schönbrunn bis St. Germain, S. 75

170 Neck, Österreich im Jahre 1918, S. 69.

171 Wolfgang Maderthaner, Die eigenartige Größe der Beschränkung. Österreichs Revolution im mitteleuropäischen Spannungsfeld, in: ... der Rest ist Österreich, hrsg. v. Helmut Konrad/Wolfgang Maderthaner (Das Werden der Ersten Republik I), Wien 2008, S. 187-206, hier S. 192. Siehe dazu auch Kleinwaechter, Von Schönbrunn bis St. Germain, S. 74. Kleinwaechter argumentierte, dass das Manifest auf die Ereignisse keinen Einfluss mehr ausgeübt habe und auch nicht beschleunigend auf den Zerfall der Monarchie eingewirkt habe. 
Dass diese schlussendlich nicht im Sinne des Manifests in einem Staatenbund aufgingen, ist dabei nebensächlich. ${ }^{172}$

\section{Fazit}

„Zu spät und halb“173 - Dieses Zitat aus der Zeitung „Arbeiterwille“ charakterisiert das Völkermanifest Kaiser Karls I. wohl am treffendsten. Es hat die Auflösung der Monarchie weder aufhalten noch verhindern können. Das Nationalitätenproblem, der Weltkrieg, und letztendlich das Zusammenspiel aus den Initiativen zahlreicher Einzelpersonen und Interessensgemeinschaften mit teilweise sehr verschiedenen Vorstellungen führten zur Entstehung des Manifests. Durch den Nichteinbezug der ungarischen Reichshälfte, allzu neutrale Formulierungen und die Meidung zentraler Probleme wie der Böhmischen Frage war es zum Scheitern verurteilt. Auch der Zeitpunkt des Erlasses war äußerst ungünstig. Das Manifest kam viel zu spät. Einerseits, weil die Alliierten bereits von der Erhaltung Österreich-Ungarns nach dem Frieden Abstand nahmen, und obendrein sogar Exilregierungen von emigrierten Politikern anerkannt hatten. Dies nicht nur als offizielle Regierung, sondern als offiziell kriegführende Macht auf alliierter Seite. Andererseits hatten sich noch vor dem Erlass des Manifests auch innerhalb der Monarchie nationale Versammlungen oder Ausschüsse - etwa von tschechischer, slowenischer, kroatischer und serbischer Seite - gebildet, die die Eigenstatlichkeit in die Wege leiten wollten. Die Hypothese vom Manifest als beschleunigendem Faktor der Auflösung sowie als Moment der Autorisierung zur Bildung von souveränen Nationalstaaten hat sich nur teilweise bewahrheitet. Zur Beschleunigung des Zerfalls des Vielvölkerstaates hat das Manifest realiter wohl nicht in einem entscheidenden Ausmaß beigetragen. Die Ereignisse hatten sich bereits vor dem Manifest überschlagen. Mit der Formulierung, dass ,jeder Volksstamm auf seinem Siedlungsgebiete sein eigenes staatliches Gemeinwesen“ bilden dürfe und sogar solle, war eine Art der Legitimation für die Eigenstaatlichkeit der nationalen Gruppen der Monarchie gegeben. Die Idee im Manifest sah aber die Bildung vieler nationaler Staaten unter dem Schirm eines Staatenbundes vor. Man wollte in gewisser Weise den supranationalen Charakter der Habsburgermonarchie in einem Bundesstaat aufrecht erhalten. Dieses Angebot wurde von den Völkern abgelehnt. Letzten Endes kann dem Manifests trotz dessen Unvollständigkeit und dem damit verbundenen vorprogrammierten Scheitern etwas Positives abgewonnen werden: Es trug seinen Teil dazu bei, dass der Zerfall des Vielvölkerstaates in weiten Teilen friedlich und ohne unnötigen Bürgerkrieg vonstatten ging.

172 Siehe auch Alois Niederstätter, Geschichte Österreichs, Stuttgart 2007, S. 217. Niederstätter ist ebenfalls der Meinung, dass das Manifest nicht nur zu spät war, sondern sogar die Auflösung des Vielvölkerreiches legitimierte.

173 Arbeiterwille, 18. Oktober 1918, [http://anno.onb.ac.at/cgi-content/anno?aid=aze\&datum=19181018\&se ite=1\&zoom=33]; eingesehen 19.07.2014 


\section{Literatur}

Albrecht, Catherine, Die Böhmische Frage, in: Cornwall, Mark (Hrsg.), Die letzten Jahre der Donaumonarchie. Der erste Vielvölkerstaat im Europa des frühen 20. Jahrhunderts, o. O. 2006, S. 85-106.

Bachleitner, Norbert/Seidler, Andrea (Hrsg.), Zur Medialisierung gesellschaftlicher Kommunikation in Österreich und Ungarn. Studien zur Presse im 18. und 19. Jahrhundert (Finno-Ugrian Studies in Austria 4), Wien 2007.

Brook-Shepherd, Gordon, Karl I. Des Reiches letzter Kaiser. Glanz und Elend des letzten österreichischen Herrscherpaares, Wien-München 1976, S. 205.

Ders., Um Krone und Reich. Die Tragödie des letzten Habsburgerkaisers, Wien 1968.

Broucek, Peter, Karl I. (IV.). Der politische Weg des letzten Herrschers der Donaumonarchie, Wien-Köln-Weimar 1997.

Domandl, Hanna, Kulturgeschichte Österreichs. Von den Anfängen bis 1938, Wien 1992.

Ehrenpreis, Petronilla, Die Reichsweite Presse in der Habsburgermonarchie, in: Rumpler, Helmut/Urbanitsch, Peter (Hrsg.), Politische Öffentlichkeit und Zivilgesellschaft. Die Presse als Faktor der politischen Mobilisierung (Die Habsburgermonarchie 1848-1918), Wien 2006, S. 1715-1818.

Hanisch, Ernst, Der lange Schatten des Staates. Österreichische Gesellschaftsgeschiche im 20. Jahrhundert, hrsg. v. Herwig Wolfram (Österreichische Geschichte 1890-1990), Wien 2005.

Höbelt, Lothar, Wohltemperierte Unzufriedenheit. Österreichische Innenpolitik 19081918, in: Cornwall, Mark (Hrsg.), Die letzten Jahre der Donaumonarchie. Der erste Vielvölkerstaat im Europa des frühen 20. Jahrhunderts, o. O. 2006, S. 58-84.

Kann, Robert A., Zur Problematik der Nationalitätenfrage in der Habsburgermonarchie 1848-1918, in: Wandruszka, Adam/Urbanitsch, Peter (Hrsg.), Die Völker des Reiches, 2. Teilb. (Die Habsburgermonarchie 1848-1918 III), Wien 1980, S. 1304-1338.

Kleinwaechter, Friedrich G. F., Von Schönbrunn bis St. Germain. Die Entstehung der Republik Österreich, Graz-Wien-Köln 1964.

Kořalka, Jiří/Crampton, R. J., Die Tschechen, in: Wandruszka, Adam/ Urbanitsch, Peter (Hrsg.), Die Völker des Reiches, 1. Teilb. (Die Habsburgermonarchie 1848-1918 III), Wien 1980, S. 489-521.

Kovács, Elisabeth, Untergang oder Rettung der Donaumonarchie? Die österreichische Frage. Kaiser und König Karl I. (IV.) und die Neuordnung Mitteleuropas (1916-1922), Bd. 1, Wien-Köln-Weimar 2004.

Lorenz, Reinhold, Kaiser Karl und der Untergang der Donaumonarchie, Graz-Wien-Köln 1959, S. 480-481. 
Maderthaner, Wolfgang, Die eigenartige Größe der Beschränkung. Österreichs Revolution im mitteleuropäischen Spannungsfeld, in: Konrad, Helmut/Maderthaner, Wolfgang (Hrsg.), ... der Rest ist Österreich (Das Werden der Ersten Republik I), Wien 2008, S. 187-206.

Malfèr, Stefan, Der Konstitutionalismus in der Habsburgermonarchie - Siebzig Jahre Verfassungsdiskussion in "Cisleithanien”, in: Rumpler, Helmut/Urbanitsch, Peter (Hrsg.), Verfassung und Parlamentarismus 1. Teilband. Verfassungsrecht, Verfassungswirklichkeit, Zentrale Repräsentativkörperschaften (Die Habsburgermonarchie 1848-1918 VII), Wien 2000, S. 11-67.

Niederstätter, Alois, Geschichte Österreichs, Stuttgart 2007.

Pleterski, Janko, Die Slowenen, in: Wandruszka,Adam/Urbanitsch, Peter (Hrsg.), Die Völker des Reiches, 2. Teilb. (Die Habsburgermonarchie 1848-1918 III), Wien 1980, S. 801-838.

Pohl, Walter/Vocelka, Karl, Die Habsburger. Eine europäische Familiengeschichte, hrsg. v. Brigitte Vacha, Wien 1992.

Rauchensteiner, Manfried, "Das neue Jahr machte bei uns einen traurigen Einzug”. Das Ende des Großen Krieges, in: Konrad, Helmut/Maderthaner, Wolfgang (Hrsg.), ... der Rest ist Österreich (Das Werden der Ersten Republik I), Wien 2008, S. 21-44.

Ders., Der Erste Weltkrieg und das Ende der Habsburgermonarchie 1914-1918, WienKöln-Weimar 2013.

Rumpler, Helmut, Das Völkermanifest Kaiser Karls vom 16. Oktober 1918. Letzter Versuch zur Rettung des Habsburgerreiches, Wien 1966.

Ders., Kaiser Karl, die Friedensprojekte und das deutsch-österreichische Bündnis, in: Gottsmann, Andreas (Hrsg.), Karl I. (IV.), der Erste Weltkrieg und das Ende der Donaumonarchie (Publikationen des historischen Instituts beim Österreichischen Kulturforum in Rom 14), Wien 2007, S. 13-22.

Stourzh, Gerald, Der Umfang der österreichischen Geschichte. Ausgewählte Studien 1990-2010 (Studien zu Politik und Verwaltung 99), Wien-Köln-Weimar 2011.

Weissensteiner, Friedrich, Die Österreichischen Kaiser. Franz I. Ferdinand I. Franz Joseph I. Karl I., Wien 2003.

\section{Quellen}

Neck, Rudolf, Österreich im Jahre 1918. Berichte und Dokumente, München 1968, S. 67-68.

Arbeiterwille, 18. Oktober 1918, [http://anno.onb.ac.at/cgi-content/anno?aid=awi\&datum $=19181018 \&$ zoom=33], eingesehen 19.07.2014.

Arbeiter Zeitung, 18. Oktober 1918, [http://anno.onb.ac.at/cgi-content/anno?aid=aze\& datum=1918101 8\&seite=1\&zoom=33]; eingesehen 19.07.2014.. 
Deutsches Volksblatt, 18. Oktober 1918, [http://anno.onb.ac.at/cgi-content/anno?aid= dvb\&datum=191 81018\&zoom=33], eingesehen 19.07.2014.

Extra-Ausgabe der Wiener Zeitung, 17. Oktober 1918, [http://anno.onb.ac.at/cgi-con tent/anno?aid=wr z\&datum=19181017\&seite=17\&zoom=33], eingesehen 25.06.2014.

Neue Freie Presse, 18. Oktober 1918, [http://anno.onb.ac.at/cgi-content/anno?aid=nfp\& datum=191810 18\&zoom=33], eingesehen 18.07.2014.

Reichspost, 18. Oktober 1918, [http://anno.onb.ac.at/cgi-content/anno?aid=rpt\&datum $=19181018 \&$ zo om=33], eingesehen 19.07.2014.

Jakob Kathrein ist Student der Bachelorstudien Geschichte und Politikwissenschaft sowie des Diplomstudiums Rechtswissenschaften an der Universität Innsbruck.

jakob.kathrein@student.uibk.ac.at

\section{Zitation dieses Beitrages}

Jakob Kathrein, "An meine getreuen österreichischen Völker". Das "Völkermanifest" Karls I. vom 16. Oktober 1918 - Ein später Versuch zur Abwendung des Zerfalls der Habsburgermonarchie?, in: historia.scribere 7 (2015), S. 33-68, [http://historia.scribere. at], 2014-2015, eingesehen 1.3.2015 (=aktuelles Datum).

(C) Creative Commons Licences 3.0 Österreich unter Wahrung der Urheberrechte der Autorlnnen. 
